Revista Brasileira de Informática na Educação - RBIE Brazilian Journal of Computers in Education (ISSN online: 2317-6121; print: 1414-5685) http://br-ie.org/pub/index.php/rbie

$\begin{array}{lll}\text { Submission: } 31 / 10 / 2021 ; & 1^{\text {st }} \text { round notif.: } 18 / 12 / 2021 ; & \text { New version: } 15 / 01 / 2021 ;\end{array}$

\title{
Desenvolvimento e Avaliação de Material Didático Desplugado para o Ensino de Computação na Educação Básica
}

\author{
Title: Design and Evaluation of Unplugged Didactic Material for Teaching of Computer \\ Science in Basic Education
}

Marcia E. J. Kniphoff da Cruz Universidade de Santa Cruz do Sul mcruz@unisc.br

\author{
Samanta Ghisleni Marques \\ Universidade de Santa Cruz do Sul \\ samantaghisleni@gmail.com
}

\author{
Wilk Oliveira \\ Universidade de São Paulo \\ wilk.oliveira@usp.br
}

\begin{abstract}
Resumo
O desenvolvimento de materiais didáticos para o Ensino de Computação, em paralelo com a formação continuada de professores, é uma urgência na Educação Básica brasileira, para fomentar o trabalho com habilidades do Pensamento Computacional nas escolas. Diante dessa necessidade, esta pesquisa teve por objetivos: i) desenvolver materiais didáticos de Computação Desplugada para o ensino de Computação na Educação Básica $\left(4^{\circ}\right.$ e $5^{\circ}$ ano do Ensino Fundamental), ii) formar professores para a compreensão de conceitos básicos da Computação e utilização do material desenvolvido em escolas da Educação Básica (rede pública de ensino); e iii) avaliar o material desenvolvido com os professores do Ensino Fundamental. A pesquisa envolveu o desenvolvimento, a avaliação do material didático e promoveu a formação continuada de professores. Os dados coletados com os professores foram categorizados e codificados para identificar a aceitação do material didático de Computação Desplugada. Os resultados mais expressivos evidenciam o material didático como "Adequado" e "Bem aceito" pelos professores, sendo que, dos sete fascículos criados os mais utilizados foram "Algoritmos" e "Reconhecimento de Padrões". Ao final dos encontros de formação continuada, identificou-se ainda que $46 \%$ dos professores demonstraram ter assimilado satisfatoriamente os conceitos trabalhados. Sendo assim, esta pesquisa demonstra que o material didático teve um alto grau de aceitação por parte dos professores, causou impacto positivos nos estudantes e também, evidencia a necessidade de novos estudos propondo e avaliando novos materiais didáticos.

Palavras-Chave: Ensino de Computação, Material Didático, Formação de Professor, Pensamento Computacional, Computação Desplugada.
\end{abstract}

\begin{abstract}
The design of didactic materials for Computer Science education, in parallel with the continued training of teachers, is an urgency in Brazilian Basic Education, to foster work with Computational Thinking skills in schools. Given this need, this research had the following objectives: $i)$ design didactic materials on Unplugged Computer Science for the teaching of Computing in Basic Education (4th and 5th grade of Elementary Education), ii) to train teachers to understand basic concepts of Computational Thinking and use the developed material in Basic Education schools (public education); and iii) evaluate the developed material with the teachers of elementary school. The research involved the design and evaluation of didactic material and promoted continuous teacher training. The data collected from the teachers were categorized and coded to identify the acceptance of the Unplugged Computer Science didactic material. The main results show the didactic material as "Adequate" and "Well accepted" by teachers, and between the created topics, the most used was "Algorithms" and "Pattern Recognition". At the end of the continuing education meetings, it was also identified that $46 \%$ of the teachers demonstrated that they had successfully assimilated the studied concepts. Therefore, this research demonstrates that the didactic material had a high degree of acceptance on the part of the teachers, caused a positive impact on the students, and also evidences the need for further studies proposing and evaluating new didactic materials.
\end{abstract}

Cite as: Cruz, M. E. J. K., Marques, S. G., \& Oliveira, W. (2021). Design and Evaluation of Unplugged Didactic Material for Teaching of Computer Science in Basic Education (Desenvolvimento e Avaliação de Material Didático Desplugado para o Ensino de Computação na Educação Básica). Brazilian Journal of Computers in Education (Revista Brasileira de Informática na Educação - RBIE), 29, 160-187. DOI: 10.5753/RBIE.2021.29.0.160 
Keywords: Computer Science Education, Didactic Material, Teacher Training, Computational Thinking, Unplugged Computer Science.

\section{Introdução}

O ensino de Computação é uma atividade desafiadora devido à alta complexidade do tópico e da necessidade de abstração de suas representações (Fincher \& Petre, 2004; Becker \& Quille, 2019; Dempster, Onah, \& Blair, 2020). Na Educação Básica (EB), de modo especial, o ensino de Computação pode ser ainda mais difícil (Proctor, Bigman, \& Blikstein, 2019), pois além do nível de complexidade inerente ao próprio assunto, é ideal que se promova um ensino associado aos tópicos abordados nas outras disciplinas do currículo da EB (ensino multidisciplinar). Ideal também, é oferecer um ensino lúdico capaz de desafiar e motivar os estudantes (Israel-Fishelson \& Hershkovitz, 2020) em um primeiro momento, realizado por professor formado em qualquer licenciatura, mas para aprofundar o estudo de Computação na escola, em um segundo momento, sendo essencial a atuação de um Licenciado em Computação (Oliveira et al. 2020).

O Ensino de Computação já se estabeleceu como uma atividade fundamental para desenvolver habilidades necessárias para o Século XXI (Mioto et al. 2019), considerando que anteriormente ao século XXI era suficiente ler, escrever e calcular, mas no século XXI é necessário ler, escrever e calcular e programar. Isso fez com que diversos países incentivassem o ensino de Computação na EB, bem como, estabelecessem currículos específicos para tal (Fletcher \& Lu 2009; Barr \& Stephenson 2011; Hubwieser et al. 2014). Assim, diversas ações têm sido feitas ao redor do mundo para efetivar o ensino de Computação na EB (Román-González, Moreno-León, \& Robles, 2019; Lee, Cheung, Ho, Yiu, \& Wu, 2019; Leonard, Daily, Jörg, \& Babu, 2020). No Brasil, de modo especial nos últimos 15 anos, algumas ações (por vezes tímidas), também têm sido feitas no intuito de seguir o modelo já conceituado de outros países (Silva Neto, Santos, \& Santos, 2015; Oliveira, Bittencourt, \& Trindade, 2019; Santana \& Oliveira, 2019), inclusive, mais recentemente com propostas de currículo com abordagem sequencial, que orienta habilidades da Computação para serem trabalhadas da Educação Infantil ao Ensino Médio (CIEB 2019; SBC 2019).

Diferente de outras áreas como Matemática, Química e Física, os materiais didáticos desenvolvidos no Brasil para o ensino de Computação na EB ainda são poucos (Santos et al. 2018; Marques, Cruz \& Schulz 2019; Oliveira et al. 2020). De modo geral, esses materiais didáticos são baseados em materiais desenvolvidos em outros países e apenas adaptados para o Português Brasileiro, não correspondendo ao nosso contexto educacional (Santos et al. 2018). Diante disso, um dos desafios atuais do ensino de Computação na EB brasileira é o desenvolvimento de materiais didáticos (Oliveira et al. 2020). Para enfrentar esse desafio, este artigo apresenta o resultado de uma pesquisa longitudinal sobre o processo de desenvolvimento, utilização e avaliação de material didático para o ensino de Computação na EB.

Por meio de pesquisa de caráter qualitativo, quantitativo, longitudinal e exploratório, o estudo encaminhado pela Universidade de Santa Cruz do Sul (UNISC), junto ao Projeto UNISC Inclusão Digital (UID) ${ }^{1}$, teve por objetivos $i$ ) desenvolver materiais didáticos de Computação Desplugada $(\mathrm{MDCD})^{2}$ para o ensino de Computação na EB ( $4^{\circ}$ e $5^{\circ}$ ano do Ensino Fundamental), ii) formar professores para a compreensão de alguns conceitos básicos da Computação e utilização do MDCD em escolas da EB (rede pública de ensino); e iii) avaliar o material desenvolvido com os professores dos respectivos anos do Ensino Fundamental. Diante dos objetivos definidos, buscouse responder e discutir as seguintes questões: $a$ ) quais são as considerações dos professores da EB

\footnotetext{
${ }^{1}$ Site do Projeto UNISC Inclusão Digital: http://projetouid.weebly.com

${ }^{2}$ Link do MDCD: https://drive.google.com/drive/folders/1135s7piskdg8ekq3mYtJlol2DgOixqqw
} 
em relação ao material didático desenvolvido? b) Quais foram os desafios (atividades) do MDCD mais utilizados em sala de aula pelos professores? e c) Como os professores assimilaram os conceitos de Computação Desplugada e Pensamento Computacional, por meio das discussões e conceitos apresentados no MDCD durante os encontros de formação?

Os principais resultados do estudo indicam que 1) foram criados 31 desafios no MDCD intitulado "Computação Desplugada na Escola"; 2) 5 professores dos 77 participantes, pertencentes a 25 escolas conseguiram utilizar todos os desafios e os demais utilizaram parte dos desafios em sala de aula; 3) ao todo foram atingidos 902 alunos nas escolas de atuação dos professores; 4) o MDCD desenvolvido necessitou ser ajustado com os professores para que assumisse uma identidade personalizada e pudesse ser melhor utilizado em sala de aula; 5) a formação de professores das escolas é melhor aproveitada em grupos pequenos, compostos por quem apresenta as mesmas necessidades; e 6) o MDCD impactou positivamente a experiência dos estudantes de $4^{\circ}$ e $5^{\circ}$ ano do Ensino Fundamental. Além disso, foi possível contribuir com a sociedade, através da disponibilização gratuita e irrestrita do MDCD desenvolvido, composto por 31 desafios distribuídos em sete fascículos.

A seguir, o artigo está estruturado da seguinte forma: Na Seção 2, apresenta-se uma revisão da literatura, com os principais tópicos abordados no estudo (i.e., Material Didático para o Ensino de Computação, Computação Desplugada e Licenciatura em Computação), bem como, os principais trabalhos relacionados. Na seção 3, apresenta-se o design do estudo. Na Seção 4, são apresentados os resultados do estudo, incluindo uma seção de lições aprendidas, contendo também uma série de recomendações para estudos futuros. Na Seção 5, apresenta-se as considerações finais acerca do estudo.

\section{Revisão de Literatura}

Nessa seção, apresenta-se uma revisão da literatura sobre os tópicos abordados neste artigo, além dos principais trabalhos relacionados.

\subsection{Material Didático para o Ensino de Computação}

O Brasil apenas iniciou movimentos para um currículo geral que de fato contemple o ensino de Computação na escola (SBC 2019; CIEB 2019). Pesquisadores brasileiros têm investido em tais ações (França \& Amaral 2013), mas, essas ações são mais focadas em utilizar ferramentas para o ensino de Computação, como jogos (Lopes, Santana \& Braga 2020) ou sistemas colaborativos (Silva \& Silva Alexandre 2020)) em projetos específicos, sem associação direta a algum currículo.

Portanto, no Brasil, ainda não se estabeleceu o desenvolvimento de materiais didáticos para o ensino de Computação na EB a nível governamental. O desenvolvimento desses materiais didáticos é, portanto, fundamental para promover uma Educação em Computação justa e igualitária, que envolva todas as escolas, independente das diversas realidades. Ao mesmo tempo, o desenvolvimento de materiais didáticos apresenta-se como uma necessidade para que o ensino de Computação possa ganhar espaço na EB, buscando estabelecer-se no mesmo nível de outras disciplinas do atual currículo da EB.

\subsection{Computação Desplugada}

Diante da necessidade do desenvolvimento de materiais didáticos para o Ensino de Computação, a criação do MDCD se justifica por ser da natureza das crianças a utilização de materiais concretos para iniciar o processo de abstração e por minimizar os efeitos da realidade das escolas brasileiras que, ainda, mostram uma ausência de recursos tecnológicos importantes para o desenvolvimento de certos tipos de materiais didáticos no Ensino de Computação. Para sanar esse problema, foi 
desenvolvido o conceito de Computação Desplugada (do inglês, Computer Science Unplugged) que se trata do desenvolvimento dos conceitos da Computação por meio de abordagens que não usam necessariamente tecnologias digitais (Bell et al. 2002; Bell et al. 2009). O documento desenvolvido pela Sociedade Brasileira de Computação (SBC), é denominado "Diretrizes para ensino de Computação na Educação Básica" e cita que: "é muito importante que o Pensamento Computacional seja trabalhado (pelo menos inicialmente) de forma desplugada (sem o uso de computadores) nos Anos Iniciais" (SBC, 2019, s/p.).

A Computação Desplugada (CD) tem sido usada em diversos países como uma alternativa para promover o Ensino de Computação nos níveis da EB (Huang \& Looi 2020), utilizando diferentes objetos simples que fazem parte do cotidiano dos próprios alunos e professores (Tonbuloglu \& Tonbuloglu 2019). Assim, as atividades de CD já têm ajudado diversos professores das escolas do mundo a melhorar a qualidade do ensino de Computação (Huang \& Looi 2020). Recentes estudos secundários (e.g., Santos et al. (2018) e Santos et al. 2019)) demonstram que no Brasil, as atividades envolvendo CD ainda são incipientes, em geral, fazem uso apenas de algumas poucas atividades para assuntos específicos, bem como, dificilmente criam novas atividades.

\subsection{Licenciatura em Computação}

A Licenciatura em Computação (LC) é um curso que foi ofertado, pela primeira vez no Brasil, no ano de 1997, com o objetivo de capacitar professores para a atuação na EB no ensino de Computação, bem como no aporte tecnológico nas escolas de EB (Santos et al. 2018). Ao longo das últimas duas décadas, de acordo com o Ministério da Educação e Cultura (MEC), mais de 100 cursos já foram criados e atualmente 85 estão ativos no Brasil, já tendo, portanto, formado diversos professores de Computação para atuação na EB (MEC 2016; SBC 2018).

Uma vez demonstrado que o ensino de Computação é visto como algo positivo já na EB (Mioto et al. 2019; Alves et al. 2019; von Wangenheim et al. 2020) a importância do curso de LC é redobrada, por ser o único curso reconhecido pelo Ministério da Educação e Cultura (MEC) destinado à formação de professores para o ensino de Computação, como definido pela Resolução CNE/CES 5/2016, publicada no Diário Oficial da União (DOU), Brasília, em 17 de novembro de 2016 (seção 1, págs. 22-24), onde são definidas as atribuições do Licenciado em Computação. Contudo, a importância do Licenciado em Computação vai além do próprio Ensino de Computação na EB, permeando outras atuações, como o desenvolvimento de materiais didáticos para o ensino de Computação (Oliveira et al. 2020).

\subsection{Trabalhos Relacionados}

Nessa seção, são apresentados e comparados uma série de estudos relacionados ao estudo proposto neste artigo. Silva Neto et al. (2015) propuseram uma abordagem para a inclusão do Licenciado em Computação de forma estruturada e integrada às disciplinas do currículo escolar. Nessa abordagem, foi demonstrado como usar diferentes materiais didáticos no ensino de Computação na EB, adaptando algumas atividades já existentes. Contudo, o estudo também não propõe a criação de materiais didáticos específicos, chamando atenção para a importância do desenvolvimento de novos materiais didáticos em Português do Brasil para o ensino de Computação na EB.

Cruz \& Becker (2017) discutem a influência da Epistemologia Genética e Neurociência Cognitiva como referências para a produção didática de estudantes de Licenciatura em Computação em uma disciplina curricular relacionada à carga horária prática. A proposta metodológica da pesquisa foi sistematizada através da elaboração de exercícios de linguagens de programação, ocorrendo antes e após o estudo dos referidos temas (CRUZ \& BECKER 2017). Os exercícios elaborados também foram direcionados para a Educação Básica e analisados segundo 
a prática computacional do Instituto de Tecnologia de Massaschusetts (Massachusetts Institute of Technology). O artigo, no entanto, não avaliou o material didático com estudantes e professores da Educação Básica, e não trabalhou a formação continuada de professores.

Marques, Cruz \& Schulz (2019) apresentaram uma pesquisa sobre a formação continuada de professores formados em LC, atuantes em escolas da rede pública. O estudo envolveu o desenvolvimento de materiais didáticos para o ensino de Computação nos anos finais da EB. Diferentes encontros foram realizados no intuito de identificar as necessidades dos professores de Informática para o desenvolvimento desses materiais. Como resultados, foram gerados materiais didáticos (em formato de apostilas) com atividades desplugadas. Os resultados demonstram a necessidade da formação continuada e a importância de desenvolver e avaliar novos materiais didáticos para o ensino de Computação na EB.

Araujo, Santana \& Bittencourt (2020) lançaram uma série de livros de atividades intitulados "Computação e Sociedade" e "Computação e o Mundo", com edições para o estudante e para o professor. Os livros contam com diversas atividades para ensinar Computação na EB. Ainda não foram realizadas avaliações dos materiais didáticos propostos, ao mesmo tempo que também fica demonstrada a necessidade do desenvolvimento e avaliação de novos materiais didáticos para o ensino de Computação na EB.

De modo geral, os estudos analisados nesta seção apresentam o desenvolvimento de material didático para o ensino de Computação na $\mathrm{EB}$, entretanto não demonstram avaliação dos referidos materiais, ou demonstram avaliações superficiais (i.e., sem aplicação das atividades em cenário real ou em larga escala). Frente a estes dados, acredita-se que o estudo apresentado neste artigo é o primeiro a propor, desenvolver e avaliar (por meio de um estudo longitudinal, em cenário real e em larga escala ${ }^{3}$ ) o MDCD para o Ensino de Computação na EB. A Tabela 1 apresenta uma comparação dos trabalhos relacionados.

Tabela 1: Trabalhos relacionados.

\begin{tabular}{|c|c|c|c|c|c|}
\hline & DMD & AMD & VMD & AMDP & APP \\
\hline Silva Neto et al. (2015) & & $\checkmark$ & & & \\
\hline Cruz \& Becker (2017) & $\checkmark$ & $\checkmark$ & & & \\
\hline Araujo, Santana \& Bittencourt (2020) & $\checkmark$ & & & & \\
\hline Marques, Cruz \& Schulz (2019) & $\checkmark$ & & & & $\checkmark$ \\
\hline Nosso estudo & $\checkmark$ & $\checkmark$ & $\checkmark$ & $\checkmark$ & $\checkmark$ \\
\hline \multicolumn{6}{|c|}{$\begin{array}{l}\text { Legenda: DMD: Desenvolve algum material didático; AMD: Aplica o material } \\
\text { didático com estudantes; VMD: Avalia o material didático; AMDP: Avalia o material } \\
\text { didático com professores; APP: Avalia os professores participantes. }\end{array}$} \\
\hline
\end{tabular}

\section{Organização do Estudo}

O estudo apresentado neste artigo buscou atingir três objetivos:

1. Desenvolver materiais didáticos de Computação Desplugada (MDCD) para o ensino de Computação na EB ( $4^{\circ}$ e $5^{\circ}$ ano do Ensino Fundamental);

2. Formar professores para a compreensão de conceitos básicos da Computação e utilização do MDCD em escolas da EB (rede pública de ensino); e

3. Avaliar o MDCD com os professores dos respectivos anos do Ensino Fundamental.

Diante dos objetivos definidos, buscou-se responder e discutir as seguintes questões:

${ }^{3}$ Avaliação do material didático em escolas de EB com aplicação para mais de 902 estudantes. 
1. Quais são as considerações dos professores da EB em relação ao material didático desenvolvido?

2. Quais foram os desafios (atividades) do MDCD mais utilizados em sala de aula pelos professores? e

3. Como os professores assimilaram os conceitos de Computação Desplugada e Pensamento Computacional, por meio das discussões e conceitos apresentados no MDCD durante os encontros de formação?

De acordo com Fontelles et al. (2009), o presente estudo pode ser classificado como misto (qualitativo e quantitativo), com abordagem longitudinal e exploratória. $\mathrm{O}$ estudo foi realizado durante 10 meses com quatro intervenções.

\subsection{Materiais e método}

Para o desenvolvimento dos materiais didáticos, foram feitos brainstorms (descritos a seguir), momento no qual os membros da equipe puderam discutir a respeito das atividades. Para a montagem das atividades foram usados os desafios impressos, cartolina, lápis e outros materiais similares. As atividades foram organizadas e distribuídas em formato de apostila.

Para avaliação do material e dos encontros de formação foram criados quatro questionários, o primeiro (Apêndice A), no mês de maio, realizou uma sondagem sobre a situação dos professores dos $4^{\circ}$ e $5^{\circ}$ ano, sobre o desempenho geral das suas turma, suas visões sobre as condições da escola, seus conhecimentos prévios sobre a diferença entre Informática e Computação e sobre como consideravam que os encontros deveriam ocorrer para que a formação apresentasse o melhor resultado possível; no segundo questionário (Apêndice B), no mês de junho, os participantes relataram suas impressões sobre o primeiro encontro e sobre as atividades desenvolvidas até o momento, o terceiro (Apêndice C), no mês de setembro, questionou sobre quais desafios foram desenvolvidos até aquele momento e quais suas concepções sobre $\mathrm{CD}$ e Pensamento Computacional e o quarto questionário (Apêndice D), no mês outubro, solicitou avaliação dos conceitos aprendidos e que os professores participantes avaliassem os encontros de formação. Para análise dos dados, foi usado o software Atlas.ti ${ }^{4}$, amplamente usado em estudos qualitativos para codificação e análise de discurso.

O estudo foi organizado em três etapas. A primeira etapa envolveu o planejamento do material didático e dos encontros de formação continuada com os professores, na segunda etapa foram desenvolvidos o material didático e os três encontros de formação com os professores, na terceira etapa ocorreu o seminário de apresentação das ações desenvolvidas nas escolas, a avaliação final do MDCD e a avaliação da formação pelos professores, conforme representado na Figura 1:

\footnotetext{
${ }^{4}$ Link para acesso: https://atlasti.com/
} 


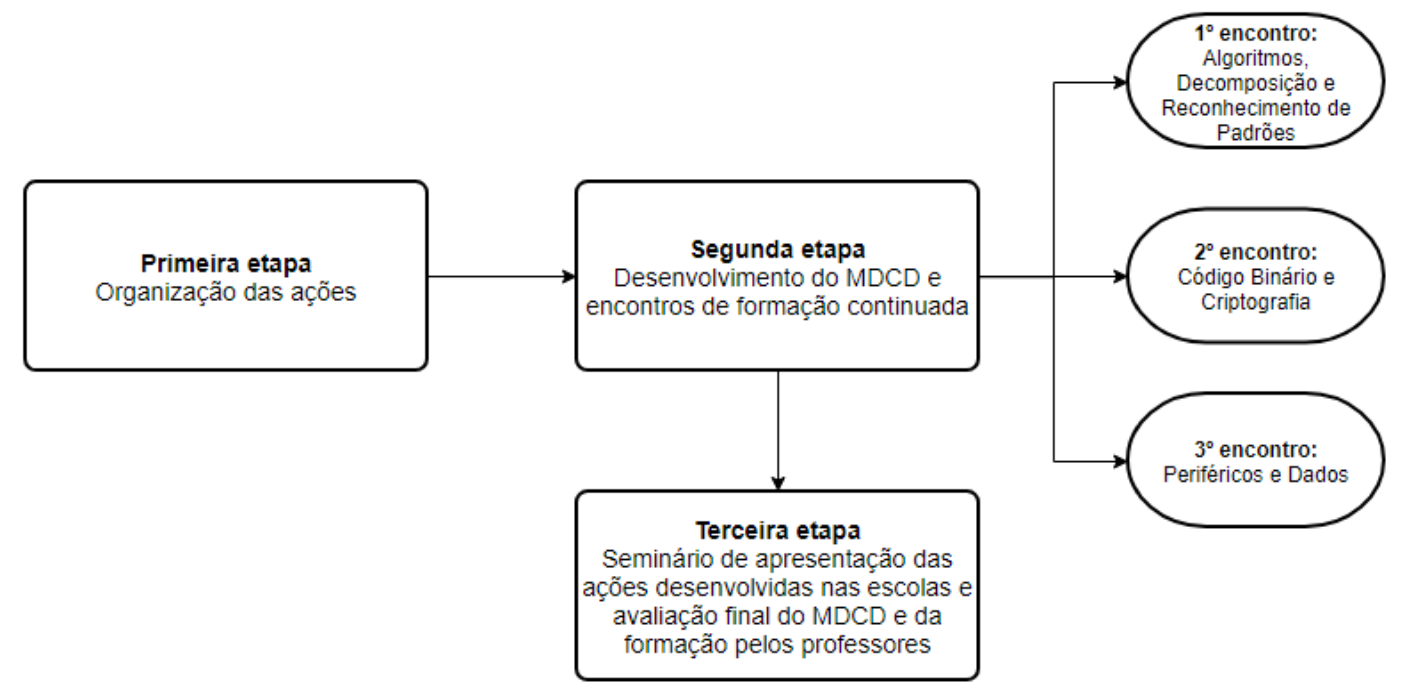

Figura 1: Representação das Etapas do Método da Pesquisa.

\subsubsection{Detalhamento das Etapas}

Na primeira etapa, foram realizadas reuniões internas da equipe de desenvolvimento do material didático, também foram ministrados os encontros de formação continuada para os professores. Esta equipe foi formada por professor, estudante e egresso de LC. Nessa etapa também foram realizadas reuniões com os gestores educacionais da rede pública de ensino, nas quais foi definido que $4^{\circ}$ e $5^{\circ}$ anos do Ensino Fundamental necessitavam de atenção especial, devido à pequena quantidade de material didático Computação Desplugada desenvolvido para essa faixa etária. Os encontros com os professores foram integrados ao cronograma de formação continuada já proposto pelos gestores da rede pública de ensino.

$\mathrm{Na}$ segunda etapa, ocorreram duas atividades: o desenvolvimento dos conteúdos do material didático intercalado aos encontros de formação dos professores. Para o desenvolvimento do material didático levou-se em consideração as diretrizes da SBC. A equipe selecionou os conceitos e dividiu o material didático em fascículos, abrangendo: Algoritmos, Reconhecimento de Padrões, Decomposição, Código Binário, Criptografia, Periféricos e Dados. Decidiu-se que as atividades do MDCD seriam apresentadas, através de conceitos e desafios ou problemas, que possuíam imagens apropriadas ao nível de ensino e faixa etária de crianças de $4^{\circ}$ e $5^{\circ}$ ano do Ensino Fundamental. Decidiu-se também, que apresentariam a versão aluno em páginas A4 prontas para impressão, na intenção de facilitar aos professores a utilização com os alunos e avaliação das atividades. Além da versão estudante, foi desenvolvida a versão professor apresentando conceitos, habilidades e gabaritos dos desafios. Todas as atividades foram pensadas no formato "desplugadas", ou seja, para serem realizadas sem o uso do computador (ver Seção 4 Resultados).

Ainda com relação a segunda etapa ocorreram três encontros de formação dos professores, com intervalo de uma a dois meses entre cada encontro, sendo que, entre os intervalos, o material didático visto no encontro anterior era aprimorado e novas atividades eram desenvolvidas. $\mathrm{O}$ principal objetivo do primeiro encontro foi realizar um brainstorm no sentido de identificar as percepções dos professores sobre o ensino de Computação na EB, seus desafios e perspectivas. Para tanto, um questionário composto por 22 questões foi desenvolvido. $26 \%$ dos professores participantes do encontro atuavam em escolas localizadas em bairros de classe média baixa. Uma grande parcela dos professores $(23 \%)$ ministrava aulas em escolas localizadas em zonas de situação de risco e vulnerabilidade social. A maioria dos professores $(63 \%)$ indicaram que, no 
geral, seus estudantes apresentam bom desempenho escolar. A cada encontro, os professores trocaram experiências sobre a utilização do MDCD nas escolas, apontando as dificuldades encontradas, a acolhida e manifestações dos estudantes. A organização dos encontros de formação foi definida segundo metodologia dialética de Vasconcelos (1992): Mobilização, Construção e Síntese:

- Mobilização: acolhida, diálogo, professores respondem questionário;

- Construção: apresentação do material didático previamente desenvolvido, diálogo e discussão;

- Síntese: combinação para utilização do MDCD em sala de aula e encaminhamentos para o próximo encontro.

O cronograma foi executado entre os meses de março a dezembro, sendo que os três encontros ocorreram em maio, junho e setembro, e o seminário ocorreu em outubro.

Na terceira etapa foi promovido um seminário, no qual os professores foram convidados a apresentar, através de relato oral, fotos e vídeos, os resultados obtidos durante a utilização do MDCD pelos alunos, comentando as contribuições das atividades para o aprendizado dos estudantes e os problemas enfrentados durante o trabalho. Os professores realizaram a avaliação dos materiais, do seu conhecimento desenvolvido neste período e avaliaram a formação, através do $4^{\circ}$ formulário de pesquisa elaborado pela equipe proponente da pesquisa. Também foi realizada reunião com os gestores da rede pública de educação para apresentação dos resultados finais.

\subsection{Participantes e análise de dados}

Participaram do estudo três pesquisadores para o desenvolvimento do material didático. A quantidade de estudantes que utilizaram as atividades foi 902 , em salas de aula de 25 escolas da rede pública de educação. A quantidade de professores participantes foi de 77. Observa-se que não faz parte do escopo deste trabalho avaliar diretamente o desempenho dos estudantes, contudo coletou-se dados trazidos pelos professores, público-alvo desta pesquisa.

Com o intuito de identificar detalhes relacionados à utilização do material em cada escola, optou-se por uma abordagem mista, com análise qualitativa e quantitativa. $\mathrm{Na}$ abordagem qualitativa de conteúdo (para responder à questão a) "Quais são as considerações dos professores da EB em relação ao material didático desenvolvido?", foram utilizadas todas as respostas do Questionário 4 (Apêndice D). Para análise dos dados foi seguido o método de Bardin (1977). A análise ocorreu em três etapas conforme recomendação de Bardin (1977):

- Organização: nessa etapa, foram organizados cada resposta em um único documento, descartando respostas inadequadas (e.g., respostas com palavras únicas, que não permitiam uma análise real da situação);

- Codificação: nessa etapa, foram definidos os códigos das análises (unidade de registro e unidade de contexto). Em nosso estudo, optou-se por não definir códigos prévios, e definir os códigos durante a leitura do material;

- Categorização: nessa etapa, foram quantificados e organizados os códigos em categorias.

Para a abordagem quantitativa (para responder à questão $b$ ) "Quais foram os desafios (atividades) do MDCD mais utilizados em sala de aula pelos professores?", foram realizadas análises de cada atividade utilizada pelos professores, em sala de aula, conforme resposta dada à questão 9 Questionário 3 (Apêndice C).

Para responder à questão c) "Como os professores assimilaram os conceitos de Computação Desplugada e Pensamento Computacional, por meio das discussões e conceitos apresentados no MDCD durante os encontros de formação?" foram analisadas as respostas 1 
e 2 do Questionário 3 (Apêndice C), segundo opinião de dois especialistas em PC, conforme classificação que segue:

- Satisfatório - respondeu demonstrando ter assimilado completamente os conceitos de PC e CD;

- Parcial - respondeu demonstrando ter assimilado os conceitos de PC e CD, mas os descreveu com menos clareza que o grau anterior;

- Insatisfatório - não correspondeu minimamente ao esperado.

\section{Resultados}

Esta seção apresenta o MDCD desenvolvido ao longo deste estudo, bem como os resultados das intervenções feitas com os participantes de estudo, respondendo às questões de pesquisa anteriormente definidas.

\subsection{O Material didático de Computação Desplugada}

O MDCD desenvolvido neste estudo foi elaborado contendo 31 desafios organizados em sete fascículos. Cada fascículos possui a seguinte quantidade de desafios: 10 sobre Algoritmos, quatro sobre Decomposição, dois sobre Reconhecimento de Padrões, oito sobre Código Binário, cinco sobre Criptografia e um sobre Periféricos e um sobre Dados, como sumarizado na Tabela 2. Os desafios foram desenvolvidos segundo as habilidades descritas nas diretrizes da SBC (SBC 2019). $\mathrm{O}$ MDCD foi desenvolvido para o $4^{\circ}$ e $5^{\circ}$ ano do Ensino Fundamental, para que o material tivesse uma sequência lógica e se tornasse de fácil compreensão, foram escolhidas habilidades de diferentes anos.

Tabela 2: Atividades que compõem o material didático.

\begin{tabular}{|c|c|c|c|c|}
\hline Id & Atividade & $\begin{array}{c}\text { Objeto de } \\
\text { conhecimento }\end{array}$ & Habilidade (SBC) & Descrição \\
\hline 1 & $\begin{array}{l}\text { Programando } \\
\text { robôs }\end{array}$ & Algoritmo & \multirow{9}{*}{$\begin{array}{l}\text { - Compreender a } \\
\text { necessidade de algoritmos } \\
\text { para resolver problemas } \\
\text { - Compreender a definição } \\
\text { de algoritmos resolvendo } \\
\text { problemas passo-a-passo } \\
\text { (exemplos: construção de } \\
\text { origamis, orientação } \\
\text { espacial, execução de uma } \\
\text { receita, etc.). } \\
\text { - Definir e simular } \\
\text { algoritmos construídos } \\
\text { como sequências e } \\
\text { repetições simples de um } \\
\text { conjunto de instruções } \\
\text { básicas (avance, vire à } \\
\text { direita, vire à esquerda...). }\end{array}$} & $\begin{array}{l}\text { Escrita de algoritmos para a } \\
\text { realização de atividades do } \\
\text { cotidiano }\end{array}$ \\
\hline 2 & $\begin{array}{l}\text { Encontrando } \\
\text { uma saída }\end{array}$ & Algoritmo & & $\begin{array}{l}\text { Escrita de sequência de comandos } \\
\text { para encontrar a saída do labirinto }\end{array}$ \\
\hline 3 & Depuração & Algoritmo & & $\begin{array}{l}\text { Analisar os algoritmos indicando as } \\
\text { correções necessárias }\end{array}$ \\
\hline 4 & Criando listas & Algoritmo & & $\begin{array}{l}\text { Escrita de materiais e ações } \\
\text { necessárias para realizar algumas } \\
\text { tarefas }\end{array}$ \\
\hline 5 & $\begin{array}{l}\text { Analisando } \\
\text { algoritmos }\end{array}$ & Algoritmo & & $\begin{array}{l}\text { Sequenciar as ações apresentadas } \\
\text { para a correta execução do } \\
\text { algoritmo }\end{array}$ \\
\hline 6 & $\begin{array}{l}\text { Encontrando } \\
\text { uma saída }\end{array}$ & Algoritmo & & $\begin{array}{l}\text { Jogo prático em que o robô e os } \\
\text { obstáculos são posicionados em } \\
\text { locais aleatórios e comandos para a } \\
\text { saída devem ser projetados }\end{array}$ \\
\hline 7 & $\begin{array}{l}\text { Descomplicand } \\
\text { o o algoritmo }\end{array}$ & Algoritmo & & $\begin{array}{l}\text { Identificar, através de um pequeno } \\
\text { texto escrito pelos estudantes, os } \\
\text { elementos principais de um } \\
\text { algoritmo }\end{array}$ \\
\hline 8 & $\begin{array}{l}\text { Criando um } \\
\text { fluxograma }\end{array}$ & Algoritmo & & $\begin{array}{l}\text { Escrita de algoritmo na forma de } \\
\text { fluxograma, compreendendo as } \\
\text { formas e funções }\end{array}$ \\
\hline 9 & $\begin{array}{l}\text { Escrevendo } \\
\text { algoritmos }\end{array}$ & Algoritmo & & $\begin{array}{l}\text { Escrita de algoritmos para as tarefas } \\
\text { listadas na forma de fluxograma }\end{array}$ \\
\hline
\end{tabular}




\begin{tabular}{|c|c|c|c|c|}
\hline 10 & $\begin{array}{l}\text { Eficiência dos } \\
\text { algoritmos }\end{array}$ & Algoritmo & & $\begin{array}{l}\text { Escrita de algoritmos para } \\
\text { deslocamento em mapa, priorizando } \\
\text { o menor número de comandos }\end{array}$ \\
\hline 11 & $\begin{array}{l}\text { Organizando } \\
\text { dados }\end{array}$ & Decomposição & \multirow{4}{*}{$\begin{array}{l}\text { Organizar objetos concretos } \\
\text { de maneira lógica } \\
\text { utilizando diferentes } \\
\text { atributos (por exemplo: cor, } \\
\text { tamanho, forma, texturas, } \\
\text { detalhes, etc.). }\end{array}$} & $\begin{array}{l}\text { Organizar as informações de acordo } \\
\text { com as categorias }\end{array}$ \\
\hline 12 & $\begin{array}{l}\text { Decompondo } \\
\text { problemas }\end{array}$ & Decomposição & & $\begin{array}{l}\text { Resolver problemas de lógica } \\
\text { através da organização de dados }\end{array}$ \\
\hline 13 & $\begin{array}{l}\text { Decomposição } \\
\text { de problemas }\end{array}$ & Decomposição & & $\begin{array}{l}\text { Organizar e ordenar valores } \\
\text { numéricos }\end{array}$ \\
\hline 14 & $\begin{array}{l}\text { Decomposição e } \\
\text { Reconhecimento } \\
\text { de padrões }\end{array}$ & Decomposição & & $\begin{array}{l}\text { Organização de materiais em listas } \\
\text { de categorias }\end{array}$ \\
\hline 15 & $\begin{array}{l}\text { Reconhecendo } \\
\text { padrões } 1\end{array}$ & $\begin{array}{l}\text { Reconhecimento } \\
\text { de padrões }\end{array}$ & \multirow{2}{*}{$\begin{array}{l}\text { Identificar padrões de } \\
\text { comportamento (exemplos: } \\
\text { jogar jogos, rotinas do dia- } \\
\text { a-dia, etc.) }\end{array}$} & $\begin{array}{l}\text { Identificar o padrão e completar a } \\
\text { sequência com formas geométricas }\end{array}$ \\
\hline 16 & $\begin{array}{l}\text { Reconhecendo } \\
\text { padrões } 2\end{array}$ & $\begin{array}{l}\text { Reconhecimento } \\
\text { de padrões }\end{array}$ & & $\begin{array}{l}\text { Criar um novo padrão de } \\
\text { preenchimento com cores }\end{array}$ \\
\hline 17 & Jogo base 2 & Código Binário & \multirow{8}{*}{$\begin{array}{l}\text { - Compreender que para } \\
\text { guardar, manipular e } \\
\text { transmitir dados precisamos } \\
\text { codificá-los de alguma } \\
\text { forma que seja } \\
\text { compreendida pela máquina } \\
\text { (formato digital). } \\
\text { - Codificar diferentes } \\
\text { informações para } \\
\text { representação em } \\
\text { computador (binária, } \\
\text { ASCII, atributos de pixel, } \\
\text { como RGB, etc.). Em } \\
\text { particular, na representação } \\
\text { de números discutir } \\
\text { representação decimal, } \\
\text { binária, etc. }\end{array}$} & $\begin{array}{l}\text { Jogo prático para a compreensão } \\
\text { dos fundamentos do binário (base 2) }\end{array}$ \\
\hline 18 & $\begin{array}{l}\text { Números } \\
\text { binários } 1\end{array}$ & Código Binário & & $\begin{array}{l}\text { Atividade para compreender a base } \\
\text { binária (base } 2 \text { ) }\end{array}$ \\
\hline 19 & $\begin{array}{l}\text { Números } \\
\text { binários } 2\end{array}$ & Código Binário & & $\begin{array}{l}\text { Correspondência entre valores } \\
\text { decimais e binários, considerando } \\
\text { os materiais do jogo base } 2\end{array}$ \\
\hline 20 & $\begin{array}{l}\text { Palavras } \\
\text { binárias }\end{array}$ & Código Binário & & $\begin{array}{l}\text { Correspondência entre a } \\
\text { representação binária e letras para a } \\
\text { escrita de palavras }\end{array}$ \\
\hline 21 & $\begin{array}{l}\text { Calculando } \\
\text { números } \\
\text { binários } 1 \\
\end{array}$ & Código Binário & & $\begin{array}{l}\text { Realizar a correspondência entre } \\
\text { números decimais e binários através } \\
\text { do uso de tabela base } 2\end{array}$ \\
\hline 22 & $\begin{array}{l}\text { Decodificando } \\
\text { com o Código } \\
\text { Binário }\end{array}$ & Código Binário & & $\begin{array}{l}\text { Realizar a correspondência entre } \\
\text { letras e sequências binárias com } \\
\text { auxílio da tabela ASCII }\end{array}$ \\
\hline 23 & $\begin{array}{l}\text { Calculando } \\
\text { números } \\
\text { binários } 2 \\
\end{array}$ & Código Binário & & $\begin{array}{l}\text { Realizar a correspondência entre } \\
\text { números decimais e binários através } \\
\text { de cálculos matemáticos }\end{array}$ \\
\hline 24 & $\begin{array}{l}\text { Números } \\
\text { binários } 3\end{array}$ & Código Binário & & $\begin{array}{l}\text { Encontrar a saída do labirinto } \\
\text { através da conversão entre binário e } \\
\text { decimal }\end{array}$ \\
\hline 25 & $\begin{array}{l}\text { Disco giratório } \\
\text { para criptografia }\end{array}$ & Criptografia & \multirow{5}{*}{$\begin{array}{l}\text { - Analisar técnicas de } \\
\text { criptografia para } \\
\text { transmissão de dados } \\
\text { segura. }\end{array}$} & $\begin{array}{l}\text { Modelo de disco giratório para a } \\
\text { criação de códigos para criptografar } \\
\text { mensagens }\end{array}$ \\
\hline 26 & Codificando & Criptografia & & $\begin{array}{l}\text { Criptografar respostas e mensagens } \\
\text { utilizando números em sequência }\end{array}$ \\
\hline 27 & Criptografia 1 & Criptografia & & $\begin{array}{l}\text { Decodificar mensagem utilizando } \\
\text { tabela com código numérico }\end{array}$ \\
\hline 28 & Criptografia 2 & Criptografia & & $\begin{array}{l}\text { Decodificar mensagem utilizando } \\
\text { tabela com código em símbolos }\end{array}$ \\
\hline 29 & Criptografia 3 & Criptografia & & $\begin{array}{l}\text { Decodificar mensagem utilizando } \\
\text { Cifra de César }\end{array}$ \\
\hline 30 & Periféricos & Periféricos & $\begin{array}{l}\text { - Compreender que para se } \\
\text { comunicar e realizar tarefas } \\
\text { o computador utiliza uma } \\
\text { interface física: o } \\
\text { computador reage a } \\
\text { estímulos do mundo } \\
\text { exterior enviados através de } \\
\text { seus dispositivos de entrada } \\
\text { (teclado, mouse, microfone, } \\
\text { sensores, antena, etc.), e } \\
\text { comunica as reações }\end{array}$ & $\begin{array}{l}\text { Identificar periféricos de entrada e } \\
\text { saída de computador }\end{array}$ \\
\hline
\end{tabular}




\begin{tabular}{l|l|l|l|l}
\hline & & & $\begin{array}{l}\text { através de dispositivos de } \\
\text { saída (monitor, alto--- } \\
\text { falante, antena, etc.) }\end{array}$ & \\
& & & $\begin{array}{l}\text { - Identificar os } \\
\text { componentes básicos de um } \\
\text { computador (dispositivos } \\
\text { de entrada/ saída, } \\
\text { processadores e } \\
\text { armazenamento) }\end{array}$ & \\
\hline 31 & Tipos de dados & Dados & $\begin{array}{l}\text { - Representar informação } \\
\text { usando símbolos ou } \\
\text { códigos escolhidos. }\end{array}$ & $\begin{array}{l}\text { Diferenciar os tipos de dados } \\
\text { processados pelo computador }\end{array}$ \\
\hline
\end{tabular}

Fonte: Os autores.

Conforme apresentado na Seção 3.1.1, o MDCD foi desenvolvido na versão aluno e professor, separados em fascículos. A Figura 2 apresenta o início de um fascículo, que na versão professor também traz habilidades e conceitos envolvidos. A Figura 3 apresenta um exemplo de desafio proposto para a compreensão do conceito de algoritmo na versão aluno (esquerda) e versão professor (direita).

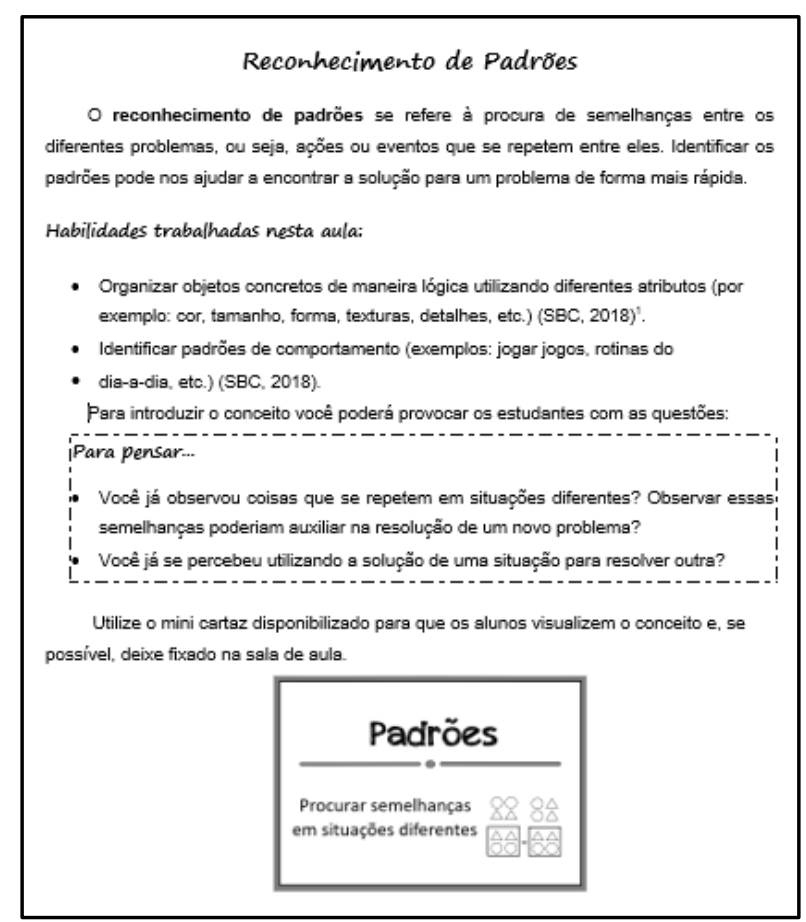

Figura 2: Página inicial do Fascículo Reconhecimento de Padrões. 


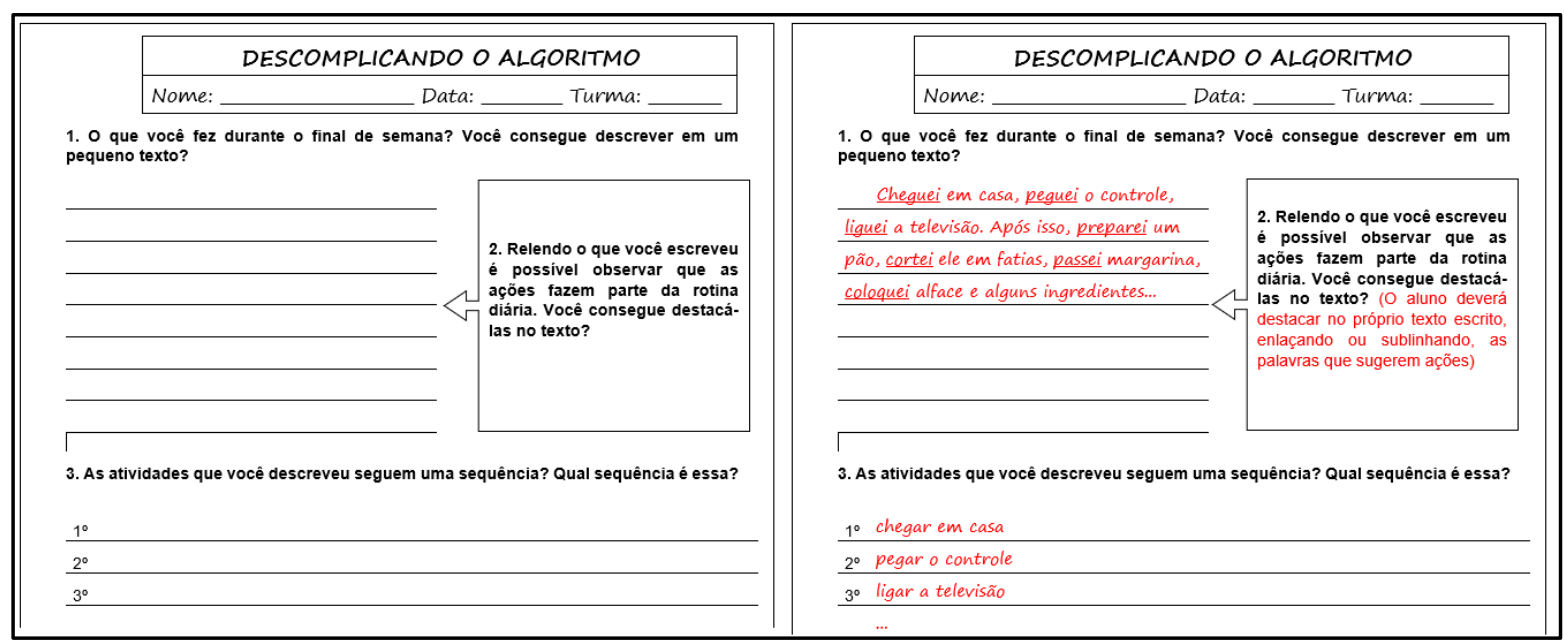

Figura 3: Exemplo de atividade sobre algoritmo.

Para a realização da atividade da Figura 3, o professor pode conversar sobre as ações que são desenvolvidas no dia a dia e propor aos alunos que as descrevam na forma de texto. A atividade convida para a análise, ou seja, o estudante identifica no seu próprio texto os elementos que compõem a escrita de algoritmos, para problemas do cotidiano, tais como utilização de verbos no infinitivo e sequenciação de ações.

\subsection{Avaliação do Material Didático de Computação Desplugada}

O material didático desenvolvido foi avaliado ao longo de três encontros de formação continuada e um seminário com os professores. No primeiro encontro, 58 professores responderam ao Questionário 1, considerado sondagem e levantamento das características e conhecimentos prévios dos professores, No segundo encontro, 59 professores responderam ao Questionário 2 sobre como foi a experiência inicial de utilização do material didático na escola, no terceiro encontro 37 professores responderam ao Questionário 3 comentando sobre a continuidade da utilização do material didático e no quarto encontro, o seminário, 42 responderam ao Questionário 4.

Para responder à questão a) "quais são as considerações dos professores da EB em relação ao material didático desenvolvido?" Foram identificados 16 códigos organizados em quatro categorias (Uso do material, Formação, Impacto nos estudantes e Sugestões), conforme supracitado (BARDIN, 1977). A maioria dos códigos foram identificados na categoria "Uso do material”, segundo a Tabela 3, que organiza os resultados dessa análise:

Tabela 3: Concepção dos professores em relação ao MDCD.

\begin{tabular}{|c|c|c|c|}
\hline Categorias & Código & Resumo & MGT \\
\hline \multirow{2}{*}{$\begin{array}{l}\text { Uso do } \\
\text { material }\end{array}$} & Adequado & $\begin{array}{l}\text { Indica que, na visão dos professores, o material foi considerado adequado } \\
\text { para o trabalho em sala de aula (e.g., "[...] os materiais disponibilizados são } \\
\text { de qualidade em termos de conteúdo"). }\end{array}$ & 36 \\
\hline & Bem aceito & $\begin{array}{l}\text { Indica que, na visão do professor, o material foi bem aceito por parte dos } \\
\text { estudantes (e.g., "como o material era interessante, os estudantes gostaram } \\
\text { muito de fazer as atividades"). }\end{array}$ & 18 \\
\hline
\end{tabular}




\begin{tabular}{|c|c|c|c|}
\hline & Lúdico & $\begin{array}{l}\text { Indica que, na visão do professor, o material apresentava atividades lúdicas } \\
\text { para os estudantes (e.g., "[...] os alunos se divertiram e tiveram outro olhar } \\
\text { sobre como raciocinar e até mesmo escrever melhor suas respostas"). }\end{array}$ & 5 \\
\hline & $\begin{array}{l}\text { Difícil } \\
\text { compreensão }\end{array}$ & $\begin{array}{l}\text { Indica que, na visão do professor, o material é difícil de ser compreendido } \\
\text { pelos estudantes (e.g., "Em algumas atividades os alunos tiveram muita } \\
\text { dificuldade, }[\ldots] ") \text {. }\end{array}$ & 2 \\
\hline & $\begin{array}{l}\text { Exige demais } \\
\text { do professor }\end{array}$ & $\begin{array}{l}\text { Indica que, na visão do professor, a aplicação do material exige demais do } \\
\text { professor em sala de aula (e.g., [...] relevantes, porém ocupa bastante tempo } \\
\text { do professor na aplicação das atividades, construção de materiais"). }\end{array}$ & 1 \\
\hline & $\begin{array}{l}\text { Pretende } \\
\text { continuar } \\
\text { usando }\end{array}$ & $\begin{array}{l}\text { Indica que o professor pretende continuar usando o material em sala de aula, } \\
\text { mesmo após o encerramento do projeto (e.g., "[...] gostei muito e vou utilizar } \\
\text { nos anos seguintes"). }\end{array}$ & 1 \\
\hline Formação & Importante & $\begin{array}{l}\text { Indica que os professores consideram importante a formação em } \\
\text { Computação Desplugada e uso do material (e.g., "Os encontros foram muito } \\
\text { positivos, pois nos proporcionaram conhecimento sobre Pensamento } \\
\text { Computacional e Computação Desplugada e sobre a necessidade de } \\
\text { trabalhar estes assuntos com nossos alunos"). }\end{array}$ & 18 \\
\hline \multirow{6}{*}{$\begin{array}{l}\text { Impacto } \\
\text { nos } \\
\text { estudantes }\end{array}$} & Reflexão & $\begin{array}{l}\text { Indica que o professor considerou que o material incentivou o pensamento } \\
\text { reflexivo dos estudantes (e.g., "[...] contribuiu muito para o desenvolvimento } \\
\text { dos alunos e sua forma de perceber e analisar de maneira diferenciada as } \\
\text { situações"). }\end{array}$ & 7 \\
\hline & $\begin{array}{l}\text { Raciocínio } \\
\text { lógico }\end{array}$ & $\begin{array}{l}\text { Indica que o professor considerou que o material didático fomentou o } \\
\text { raciocínio lógico dos estudantes (e.g., "O impacto das atividades foi ótimo, } \\
\text { ativou o raciocínio lógico matemático dos estudantes"). }\end{array}$ & 3 \\
\hline & Abstração & $\begin{array}{l}\text { Indica que o professor considerou que o material incentivou a abstração dos } \\
\text { estudantes (e.g., [...] conseguiram (os estudantes) usar em outras atividades, } \\
\text { conseguindo realizar com mais facilidade"). }\end{array}$ & 1 \\
\hline & Autonomia & $\begin{array}{l}\text { Indica que o professor considerou que o material ajudou na autonomia dos } \\
\text { estudantes (e.g., "O que mais me chamou atenção, foi a habilidade que } \\
\text { alunos com pouco rendimento em outras disciplinas desenvolveram de } \\
\text { forma autônoma e com vontade todas atividades solicitadas e foram muito } \\
\text { bem"). }\end{array}$ & 1 \\
\hline & Envolvimento & $\begin{array}{l}\text { Indica que o professor considerou que o material estimulou o envolvimento } \\
\text { dos estudantes (e.g., "Fiquei surpreendida com o impacto e envolvimento } \\
\text { dos alunos nas atividades de computação }[\ldots] \text { "..). }\end{array}$ & 1 \\
\hline & $\begin{array}{l}\text { Organização } \\
\text { do pensamento }\end{array}$ & $\begin{array}{l}\text { Indica que o professor considerou que o material incentivou a organização } \\
\text { do pensamento de seus estudantes (e.g., [...] que a realização das mesmas } \\
\text { (atividades) trouxe, principalmente, organização do pensamento dos } \\
\text { alunos"). }\end{array}$ & 1 \\
\hline Sugestões & $\begin{array}{l}\text { Novas } \\
\text { atividades }\end{array}$ & $\begin{array}{l}\text { Professores sugerindo o desenvolvimento de novas atividades para } \\
\text { incrementar o material (e.g., "[...] outras atividades sejam incluídas além das } \\
\text { já oferecidas"). }\end{array}$ & 12 \\
\hline
\end{tabular}




\begin{tabular}{|l|l|l|l}
$\begin{array}{l}\text { Parceria com } \\
\text { os professores }\end{array}$ & $\begin{array}{l}\text { Sugestões para o desenvolvimento de novas atividades junto com os } \\
\text { professores ("Construção de material didático nos encontros"). }\end{array}$ & 2 \\
\hline $\begin{array}{l}\text { Atividades } \\
\text { personalizadas }\end{array}$ & $\begin{array}{l}\text { Sugestão para a criação de atividades específicas para cada turma/ano (e.g., } \\
\text { "[...] atividades diferentes para o } 4^{\circ} \text { e } 5^{\circ} \text { ano"). }\end{array}$ & 1 \\
\hline $\begin{array}{l}\text { Recursos para } \\
\text { o professor }\end{array}$ & $\begin{array}{l}\text { Sugestão para a criação de recursos específicos para o professor (e.g., "[...] } \\
\text { conteúdo específicos para professores, que auxiliem os mesmos, para } \\
\text { trabalhar com os alunos"). }\end{array}$ & 1 \\
\hline
\end{tabular}

Legenda: MGT - Magnitude; Textos entre aspas indicam recortes de textos dos professores;

Como apresentado na Tabela 3, o código mais frequente foi "Adequado" na categoria "Uso do material" com 36 ocorrências, indicando que em geral, os professores consideraram que o material didático desenvolvido é adequado para o Ensino de Computação na $\mathrm{EB}$, o que revela que o material didático também pode ser usado em outros contextos. Ao mesmo tempo, o código "Bem aceito", pertencente à mesma categoria, foi diagnosticado 18 vezes, reforçando que os professores tiveram uma grande aceitação com relação à qualidade do material desenvolvido. $O$ código "Lúdico" ocorre 5 vezes e torna evidente que parte dos professores considerou o material atraente e divertido. Considera-se que o valor deste código foi atribuído em função do grau de abstração que o material exige, em contraponto o código "Difícil compreensão" aparece somente 2 vezes, destacando que, o material sugere ser compreensível. O MDCD, na mesma categoria, é considerado por exigir demais do professor somente uma vez, assim como "Pretende continuar usando". Considera-se que esse código tenha relação com a categoria "Sugestões", código "Novas atividades", uma vez que tem 12 apontamentos. Se os professores esperam por novas atividades, entende-se que pretendem continuar utilizando o material.

Na categoria "Formação", o código "Importante" foi identificado 18 vezes, o que aponta que os professores consideram os conceitos da Computação e, em especial, do PC, importantes para a formação docente e ensino na escola.

Ao considerar em "Impacto nos estudantes", o código "Reflexão" com sete apontamentos foi o mais frequente seguido de "Raciocínio lógico" com três indicações. Estas considerações mostram que os desafios que compõem o material didático promovem o pensar dos estudantes para a sua realização. $\mathrm{Na}$ mesma categoria, os códigos "Autonomia", "Envolvimento", "Abstração" e "Organização do pensamento" apareceram uma vez cada, indicando que ocorreu a percepção por parte dos professores na relação entre os desafios propostos e a dedicação dos estudantes em resolvê-los.

A categoria "Sugestão" aponta as ideias dos professores para a continuidade do trabalho, tendo sido pontuado uma vez "Atividades personalizadas" e "Recursos para o professor". O código mais relevante, com 12 indicações foi "Novas atividades", apontando que uma grande parte dos professores gostaram da forma como os desafios foram apresentados e têm o desejo de continuar a desenvolver em suas aulas, atividades sobre Computação e Pensamento Computacional. Observa-se dois apontamentos para "Parceria com os professores".

Respondendo à questão $b$ ) "quais foram os desafios (atividades) mais utilizados em sala de aula pelos professores?" Identifica-se que foram aqueles que envolviam conceitos relacionados a Algoritmos e Reconhecimento de Padrões. As atividades menos utilizadas abordam o fascículo Código Binário. Estes dados apontam que os professores trabalharam, em 
sua maioria, os conceitos iniciais do que foi apresentado nos encontros de formação, sem aprofundar os demais tópicos tratados no material.

Para responder à questão c) "como os professores assimilaram os conceitos de Computação Desplugada e Pensamento Computacional, por meio das discussões e conceitos apresentados no MDCD durante os encontros de formação?" são consideradas respostas às questões 1 e 2, feitas no Questionário 3 (Apêndice C), a respeito do entendimento sobre CD e PC. Como resposta à pergunta de número $1,46 \%$ dos professores conseguiram responder satisfatoriamente, conceituando de forma correta e completa o conceito de $\mathrm{CD}$, como pode ser visto na afirmação de um dos participantes "Computação Desplugada é o ensino da Computação sem o uso do computador", $35 \%$ respondeu de forma parcial, sendo que os termos utilizados não demonstram total clareza sobre o conceito e 19\% responderam de forma insatisfatória.

Na pergunta de número $2,46 \%$ dos professores responderam coerentemente, apresentando conceito "satisfatório" para PC, $22 \%$ não demonstrou total clareza ao conceituar e $32 \%$ demonstrou não compreender o conceito trabalhado durante os encontros de formação. Essa afirmação é evidenciada na resposta de um dos participantes, quando afirma que PC "É o processo lógico que o computador faz para ele, usando seus comandos". A Tabela 4 indica os percentuais de resposta em cada classificação:

Tabela 4: Considerações sobre a assimilação dos professores em relação aos conceitos de CD e PC.

\begin{tabular}{c|c|c|c}
\hline Conceito & Satisfatório & Parcial & Insatisfatório \\
\hline CD & $46 \%$ & $35 \%$ & $19 \%$ \\
\hline PC & $46 \%$ & $22 \%$ & $32 \%$ \\
\hline Legenda: CD: Computação Desplugada; PC: \\
Pensamento Computacional.
\end{tabular}

A Tabela 4 demonstra que a quantidade de professores que conceituou CD e PC somente de forma parcial ou insuficiente somados, corresponde a mais da metade do grupo, ou seja, 54\%. Indicando que o trabalho desenvolvido necessita ter continuidade e novas propostas na área devem ser pensadas para que mais professores consigam assimilar tais conceitos.

\subsection{Discussão}

Esta pesquisa objetivou desenvolver material didático de Computação Desplugada para os $4^{\circ}$ e $5^{\circ}$ ano do Ensino Fundamental. O desenvolvimento do material didático ocorreu concomitante com três encontros de formação continuada para 77 professores. Foi possível oportunizar a 902 crianças, de 25 escolas, o aprendizado de conceitos da Computação, através da disponibilização do MDCD aos seus professores. As diversas etapas desta pesquisa remetem a uma visão otimista, mas crítica em relação à trajetória percorrida. Otimista enquanto recorda-se momentos dos encontros de formação em que muitos professores se mostravam felizes e engajados no processo de aprendizagem sobre PC, CD e auxiliando na revisão do MDCD. Críticos ao deparar com um dado que prendeu a atenção e que se refere à quantidade decrescente de professores respondentes do primeiro ao terceiro questionário. Isso se deve possivelmente ao fato de que o número de professores foi decaindo e remete à reflexão sobre a formação continuada ser encarada por parte dos participantes como uma obrigação e não como um aperfeiçoamento da sua prática. No geral, considera-se que menos da metade dos professores estava plenamente engajado com a proposta, favorável a contribuir com a pesquisa e considerando as habilidades de PC como essenciais de serem trabalhadas nas escolas.

A composição do MDCD, segundo as habilidades apresentadas pelas diretrizes da SBC oportunizaram a direção a ser seguida no desenvolvimento dos desafios contidos em cada fascículo do material. É importante salientar que as habilidades facilitaram o desenvolvimento e 
que podem ser, na realidade, direcionadas a todos os anos da $\mathrm{EB}$, dependendo do grau de dificuldade com que se elaboram os desafios. Foi considerado que os $4^{\circ}$ e $5^{\circ}$ ano não haviam trabalhado, anteriormente com conceitos de PC, assim, o MDCD traz atividades acessíveis e divertidas, capazes de contribuir para o ensino de Computação na escola, trazendo, portanto, uma contribuição ainda não abordada por estudos anteriores. Ao mesmo tempo, considera-se que a produção do MDCD e a execução do processo foi uma atividade complexa, por envolver análise de respostas dadas aos questionários, pelos professores e suas considerações. A avaliação do MDCD trouxe diferentes apontamentos que possibilitaram aprimorar o material produzido entre os encontros de formação.

Conforme Falkembach (2015), após a concepção, o material didático precisa ser bem aceito pelos professores e estudantes, bem como, ser considerado adequado para que possa ser usado em sala de aula. Diante disso, o material didático apresentado nesse estudo foi bem aceito pelos professores, como indicado nos códigos "Adequado" e "Bem aceitos" da categoria "Uso do material", com 36 e 18 ocorrências respectivamente (ver Quadro 3). Conforme a premissa de Falkembach (2015), fica evidente que o material proposto pode ser considerado adequado para uso em sala de aula.

Apesar da excelente ocorrência nos códigos já citados, há apenas uma ocorrência para "Pretende Continuar Usando", o que faz inferir que o material didático e os conceitos trabalhados nos encontros de formação podem não ter sido encarados como necessários e permanentes pelos professores, mas como uma experiência pontual que não precisa ser incorporada ao escopo dos conteúdos dos $4^{\circ}$ e $5^{\circ}$ anos do Ensino Fundamental. Essa atitude por parte dos professores pode ser reflexo da deficiência na sua formação inicial, que não aborda conhecimentos para o ensino de Computação no Brasil.

Na categoria "Impacto nos estudantes", os seis códigos apresentados denotam excelentes habilidades necessárias ao desenvolvimento do Pensamento Computacional. O desejo de "Novas atividades" apontado na Tabela 3, na categoria "Sugestões" remete à equipe proponente do estudo, o compromisso de, futuramente, desenvolver materiais complementares ao MDCD.

Os desafios mais utilizados pelos professores em sala de aula, também foram analisados, sendo: Algoritmos, Reconhecimento de Padrões e Código Binários. Considera-se que mais desafios poderiam ter sido utilizados pelos professores, pois no seminário final, realizado após o terceiro encontro, somente cinco professores relataram ter utilizado todos os desafios do MDCD, o que destoa de 12 ocorrências no código "Novas atividades", na Tabela 3.

Retomando as atividades menos utilizadas (que abordam o fascículo Código Binário), na observação realizada durante os encontros de formação, nota-se que desafios computacionais com um maior grau de abstração são considerados difíceis de serem trabalhados pelos professores formados em licenciaturas, que não Licenciatura em Computação, o que reforça o proposto na BNC-Formação (2019), a necessidade da obrigatoriedade do estudo de Pensamento Computacional nas licenciaturas de todas as áreas. Esta obrigatoriedade resultará em um saudável processo de ensino de Computação na escola de EB, iniciada por professores formados em diferentes áreas, encaminhada, continuada e aprimorada pelos Licenciados em Computação.

Para que o aprendizado dos estudantes na escola seja significativo, é importante que os professores tenham domínio sobre os conceitos que são abordados no MDCD. No momento de mobilização do primeiro encontro foi realizado um pequeno teatro para que os professores percebessem que a encenação se tratava de um algoritmo, porém nenhum foi capaz de citar este termo, além disso ficou evidente o desconhecimento da maioria dos professores sobre a diferença entre Informática e Computação, conforme respostas dadas às perguntas 8 e 8.1, do Questionário 1 (Apêndice A), em que 47\% respondeu saber que há diferença entre os termos, mas não saberia explicar qual é. É importante ressaltar que, após o primeiro encontro, novas estratégias para 
esclarecer os conceitos sobre CD e PC foram traçadas para os momentos de formação seguintes. Porém, a quantidade de respostas classificadas como "satisfatório" para identificar professores que assimilaram o conceito de $\mathrm{PC}$ e $\mathrm{CD}$, manteve um baixo percentual, em relação ao tempo de duração da pesquisa, a quantidade de encontros e a intensidade das atividades desenvolvidas com os professores.

Com base nos resultados, ainda, considera-se que o apontamento do código "Lúdico", no Quadro 3 é o conceito mais pertinente para CD e o que melhor caracteriza o seu sentido. O "lúdico" tem como princípio tornar um conteúdo complexo em um conteúdo mais acessível à compreensão, por fazer uso de jogos ou brincadeiras. Com este sentido, o MDCE foi desenvolvido e pode contribuir para a introdução da Computação nas escolas brasileiras.

Como mencionado anteriormente, a equipe proponente do projeto foi composta por um professor de LC, um estudante de LC e um egresso de LC. Destaca-se que a formação dos componentes da equipe foi essencial, uma vez que grade curricular da LC da UNISC, oferece disciplina denominada "Produção de Materiais didáticos" que visa preparar o estudante no sentido do desenvolvimento de materiais didáticos com um padrão elevado de qualidade, envolvendo aspectos técnicos e didáticos. Considerando-se que a qualidade é destacada na produção de "desafios" que diferem de meros exercícios, pois desafios possuem o propósito de "fazer pensar", enquanto exercícios possuem a principal função de repetição de um conteúdo para a fixação do mesmo. Nesse sentido, fica demonstrado a importância do Licenciado em Computação na produção de materiais didáticos para o Ensino de Computação.

Considerando que a RESOLUÇÃO CNE/CP N 2, DE 20 DE DEZEMBRO DE 2019 (BNC-Formação), institui nas 800 horas obrigatórias, desde o início do curso para todas as licenciaturas, devendo incluir a temática "compreensão básica dos fenômenos digitais e do pensamento computacional, bem como de suas implicações nos processos de ensinoaprendizagem na contemporaneidade" (MEC 2020), este trabalho é referência para a concretização da referida temática que estará presente na formação de professores de todas as áreas do conhecimento, tendo em vista que os resultados do estudo atingiram professores dos anos iniciais do Ensino Fundamental, formados, no geral, em Pedagogia.

Em resumo, este estudo propôs, desenvolveu e avaliou MDCE para uso na Educação Básica ( $4^{\circ}$ e $5^{\circ}$ ano), bem como, conduziu encontros de formação continuada para professores da rede pública de ensino, nos quais os mesmos puderam usar o material didático ao longo de 10 meses e assimilar conceitos de PC e CD. Os resultados permitiram identificar que o material didático foi bem aceito pelos professores e referenda estudante, ex-aluno e professor de Licenciatura em Computação como protagonistas do processo de criação. Esta pesquisa realizada em uma única região brasileira pode ser ponto de partida para outras diferentes propostas, que somadas possam refletir um país atuante no ensino de Computação na Educação Básica.

Essa soma de partes deve conter em seu âmago direções uniformizadas que possam refletir coesão e exercício do pleno direito do cidadão brasileiro à educação, sendo que, a Base Nacional Comum Curricular (BNCC) afirma: "Temos um documento relevante, pautado em altas expectativas de aprendizagem, que deve ser acompanhado pela sociedade para que, em regime de colaboração, faça o país avançar" (BRASIL, 2019). Hoje não se pode desconsiderar que a escola não traz ao estudante o que é mais urgente à sociedade: o aprendizado de Computação como uma forma de capacidade criativa e de equidade sociocultural. Essa direção uniformizada pode ser

\footnotetext{
5 "lúdico", relativo a jogo ou divertimento. = RECREATIVO. Que serve para divertir ou dar prazer. in Dicionário Priberam da Língua Portugues, 2008-2020, https://dicionario.priberam.org/1\%C3\%BAdico [consultado em 28-102020].
} 
inspirada nesta pesquisa e deve partir do governo brasileiro, para que todo cidadão seja contemplado.

\subsection{Limitações}

O estudo apresentado neste artigo possui algumas limitações inerentes ao próprio caráter do estudo e que devem ser consideradas na interpretação dos resultados e em futuras reedições/replicações do estudo. Inicialmente os questionários usados no estudo não foram validados estatisticamente. Para mitigar essa limitação, os questionários foram desenvolvidos e avaliados por especialistas no domínio do estudo. Outra limitação diz respeito aos professores que participaram do estudo, que são de um único estado do Brasil e por isso as situações e opiniões relatados podem ser, somente, parcialmente generalizadas para o contexto de outros estados da federação. Considerando essas premissas, sugerimos que futuros estudos possam avaliar o material didático em outros estados com diferentes realidades educacionais e condições socioeconômicas.

Com relação ao método de análise do estudo, por usarmos uma estratégia em sua maioria qualitativa, pontos específicos podem não ter sido considerados. Para amenizar essa limitação, esta pesquisa utilizou um procedimento reconhecido para a condução do tipo de estudo e contou com o auxílio de software para organização da análise. Finalmente, o material didático desenvolvido no estudo apresenta desafios de Computação Desplugada para o $4^{\circ}$ e $5^{\circ}$ ano do Ensino Fundamental, pois foram criados conforme as condições e necessidades locais da referida rede pública de ensino. Diante disso, é importante que estudos futuros possam incluir novas habilidades básicas da Computação e possam ser utilizados com diferentes anos (turmas) de estudantes e outros níveis de ensino da EB.

\subsection{Lições aprendidas e recomendações para a comunidade}

Diante dos resultados do estudo, diferentes lições foram aprendidas, permitindo a composição de recomendações para a comunidade. Essas lições e recomendações são divididas em quatro campos de conhecimento baseados em questões não analisadas anteriormente e nos diálogos ocorridos nos encontros de formação que oportunizaram formar saberes latentes. Os quatro campos de conhecimento são: $i$ ) conhecimentos sobre a formação continuada de professores da EB; ii) conhecimentos sobre a produção de materiais didáticos para ensino de Computação na escola; iii) conhecimentos sobre o esclarecimento de gestores para introdução do ensino de Computação na escola; e $i v$ ) conhecimentos sobre o alcance aos estudantes nas escolas:

i. conhecimentos sobre a formação continuada de professores da EB: os professores da EB, no geral, participam de momentos de formação e devem cumprir uma determinada carga horária com formação continuada proposta pela rede de ensino à qual pertencem, o que, certamente, deveria aperfeiçoar o fazer didático. Observa-se que os professores preferem capacitações focadas, em pequenos grupos, conforme respondido no Questionário 1, pergunta 1.1 (Apêndice A) e que, efetivamente, contribuam no andamento das aulas, no trabalho do professor, apresentando e discutindo conteúdos que possam ser aplicados. Verificou-se, ainda que, enquanto alguns professores demonstraram receptividade ao novo aprendizado e ao MDCD da formação, outros não "levaram a sério" o início das atividades, sendo que por exemplo, 19 professores chegaram ao $2^{\circ}$ encontro sem ter utilizado nenhuma atividade do material didático apresentado, conforme resposta da Pergunta 2, do Questionário 2 (Apêndice B) e ficaram surpresos de precisar responder questionário objetivo sobre as suas ações. Refletindo a respeito disso, indaga-se que há a possibilidade da maioria das formações anteriormente propostas terem sido abstratas, não contribuindo com o cotidiano do professor. Diante do exposto, para futuras ações de pesquisadores que pretendam trabalhar com formação de professores, sugerimos que sejam 
realizados encontros prévios para organização dos cursos em conjunto com os professores, considerando suas expectativas.

ii. conhecimentos sobre a produção de materiais didáticos para ensino de Computação na escola: nesse aspecto foi possível aprofundar vários conhecimentos, sendo que, o mais relevante diz respeito à necessidade de envolver os professores no processo de produção do material didático. No momento em que os professores dos $4^{\circ}$ e $5^{\circ}$ ano foram convidados a opinar e sugerir alterações, durante os diálogos dos encontros de formação, uma quantidade significativa de professores demonstrou sentir responsabilidade sobre a aplicação dos materiais didáticos com suas turmas de alunos. Este conhecimento reforça a indicação anterior aos pesquisadores que desejarem trabalhar com formação docente continuada.

iii. conhecimentos sobre o esclarecimento aos gestores para introdução do ensino de Computação na escola: a reunião com gestores da rede pública de escolas foi facilitada pela proximidade e confiança conquistadas em atividades anteriores e observou-se que os gestores desconheciam o que é Pensamento Computacional e Computação. Salienta-se que os gestores demonstraram muita receptividade à pesquisa e intenção de ampliar para outros anos de ensino. Em futuras pesquisas, recomenda-se aos proponentes que façam um trabalho prévio mais elaborado com os gestores educacionais para assegurar continuidade de utilização do material didático em questão, após a conclusão da formação.

$i v$. conhecimentos sobre o alcance aos estudantes nas escolas: solicitar aos professores fotos e vídeos da utilização do MDCD com os estudantes das escolas foi um ponto muito produtivo. Foi possível observar o interesse das crianças sobre o material didático que foi, por elas, considerado interessante. Os professores relataram que para o $4^{\circ}$ ano o material é um pouco aprofundado e para o $5^{\circ}$ ano é ideal. Sugerimos para trabalhos de futuras pesquisas que os proponentes elaborem instrumentos de coleta de dados (respeitando os devidos valores éticos) voltados a conhecer mais profundamente as turmas de alunos envolvidas e possam conhecer mais especificamente o desempenho dos alunos durante a utilização do material didático em sala de aula.

\section{Considerações Finais}

O desenvolvimento de material didático para o ensino de Computação na EB, no Brasil, ainda ocorre em atividades pontuadas, assim como, a formação de professores. A Resolução CNE/CP $\mathrm{n}^{\circ}$ 2, publicada pelo MEC em 20 de dezembro de 2019 aponta como obrigatória a abordagem de Pensamento Computacional para formação inicial de professores em todas as áreas de conhecimento. A partir da homologação desta resolução os currículos das licenciaturas possuem dois anos para adequação. Assim, os trabalhos encaminhados como o desta pesquisa, corroboram para o ensino de Computação nas escolas e que a incorporação de "Pensamento Computacional" à referida Resolução é um reflexo positivo dos resultados dos trabalhos.

Esta pesquisa possibilitou a construção de conhecimentos tanto sobre como criar material didático, quanto sobre como desenvolver a formação continuada de professores para o ensino de Computação na Educação Básica. Foi possível identificar que o material didático é melhor recebido se quem deve utilizar, neste caso, os professores, foram envolvidos no processo de criação, pois desenvolvem um senso de pertencimento e responsabilidade relacionado. Ficou evidente que a escolha de intercalar a criação do MDCD com os encontros de formação continuada corrobora para a boa aceitação do material didático, pois a cada encontro os materiais produzidos eram analisados e alterados, conforme contribuições dos professores. Outro aspecto que torna evidente e permite concluir que os encontros de formação continuada foram significativos para os professores são os códigos presentes na categoria "Impacto nos estudantes", termos estes, todos voltados à habilidades essenciais às bases do ensino da Computação na escola. Em relação à 
quantidade de materiais didáticos utilizados, percebemos que é ideal em um ano letivo construir a proposta em conjunto com os professores e sugerimos efetivar no ano seguinte, para que todos os materiais possam ser utilizados. Outro fator intrínseco ao sucesso da pesquisa se relaciona à formação da equipe proponente, composta por professor, aluno e ex-aluno de Licenciatura em Computação, o que permite identificar que os resultados dependem da expertise dos integrantes relacionados ao propósito do trabalho. Ainda, os resultados da pesquisa possivelmente devem-se ao contexto dos encontros de formação terem sido integralmente presenciais, o que leva à reflexão que em contexto da situação causada pela pandemia da COVID-19, seria possível adaptar os encontros ao ensino remoto.

Espera-se que, em um pequeno período de tempo, o Brasil desenvolva mecanismos para o efetivo ensino de Computação nas escolas de EB, permitindo a todas as crianças e adolescentes a oportunidade de aprendizado, com materiais didáticos apropriados. Concluímos que o MDCD desenvolvido e avaliado nesta pesquisa, bem como a os resultados da formação realizada com os professores dos $4^{\circ}$ e $5^{\circ}$ ano, contribui para discussões sobre como e quais caminhos adotar para que o ensino de Computação na escola brasileira possa ser encaminhado pelo MEC. As lições aprendidas nos permitem planejar o desenvolvimento de novos materiais didáticos, em especial, para anos anteriores $\left(1^{\circ}, 2^{\circ}\right.$ e $\left.3^{\circ}\right)$, uma vez que, já existem materiais desenvolvidos para $6^{\circ}$ e $7^{\circ}$ ano, conforme descrito na seção 2.4 (Trabalhos Relacionados). A continuação do desenvolvimento está prevista para o ano de 2021, bem como o licenciamento do MDCD na Creative Commons.

\section{Agradecimentos}

Agradecemos à Universidade de Santa Cruz do Sul (UNISC) por proporcionar um ambiente ideal para desenvolvimento do MDCD e demais atividades relacionadas aos projetos: Projeto UNISC Inclusão Digital e projeto parceiro "O uso de estilos cognitivos e de agentes pedagógicos no processo de ensino aprendizagem em ambientes virtuais"; aos professores da rede pública de ensino, à Associação de Entidades Empresariais do município em questão, pelo fomento financeiro.

\section{Referências}

Alves, N., von Wangenheim, C. G., Hauck, J., Borgatto, A., \& Andrade, D. (2019). Uma Análise do Sequenciamento Pedagógico no Ensino de Computação na Educação Básica. In Simpósio Brasileiro de Informática na Educação (Vol. 30, No. 1, p. 1). DOI: 10.5753/cbie.sbie.2019.1 [GS Search]

Araujo, L., Santana, B., \& Bittencourt, R. (2020). Computação e o mundo: Livro do professor. Feira de Santana:[sn]. [GS Search]

Araujo, L., Santana, B., \& Bittencourt, R. (2020). Computação e o mundo: Livro do estudante. Feira de Santana:[sn]. [GS Search]

Bardin, L. (1977). Análise de conteúdo. Lisboa: edições, 70, 225. [GS Search]

Barr, V., \& Stephenson, C. (2011). Bringing computational thinking to K-12: what is Involved and what is the role of the computer science education community?. Acm Inroads, 2(1), 4854. (Vol. 2, No. 1). DOI: 10.1145/1929887.1929905 [GS Search]

Becker, B. A., \& Quille, K. (2019). 50 years of cs1 at sigcse: A review of the evolution of introductory programming education research. In Proceedings of the 50th acm technical 
symposium on computer science education (pp. 338-344). DOI: $\underline{10.1145 / 3287324.3287432}$ [GS Search]

Bell, T., Alexander, J., Freeman, I., \& Grimley, M. (2009). Computer science unplugged: School students doing real computing without computers. The New Zealand Journal of Applied Computing and Information Technology, 13(1), 20-29. [GS Search]

Bell, T., Witten, I. H., \& Fellows, M. (2002). Computer science unplugged. [GS Search]

Brasil. Base Nacional Comum Curricular (BNCC). Educação é a Base. Brasília, MEC, 2017. http://basenacionalcomum.mec.gov.br/images/BNCC_EI_EF_110518_versaofinal_site.pdf. Acesso em, 22 de outubro de 2020.

Brasil, Ministério da Educação e Cultura - MEC. RESOLUÇÃO CNE/CP No 2, DE 20 DE DEZEMBRO DE 2019. http://portal.mec.gov.br/docman/dezembro-2019-pdf/135951rcp002-19/file Acesso em, 11 de janeiro de 2021.

Centro de Inovação para a Educação Brasileira - CIEB (2019). https://curriculo.cieb.net.br/. Acesso em 15 de setembro de 2020.

Cruz, M. K. \& Becker, F. (2017). Produção Didática para Ensino de Computação Temas e Sentimentos. XXV Ciclo de Palestras sobre Novas Tecnologias da Educação (pp. 239-248) [GS Search]

Dempster, P., Onah, D., \& Blair, L. (2020). Increasing academic diversity and interdisciplinarity of Computer Science in Higher Education. In Proceedings of the 4th Conference on Computing Education Practice 2020 (pp. 1-4). DOI: 10.1145/3372356.3372366 [GS Search]

Falkembach, G. A. M. (2005). Concepção e desenvolvimento de material educativo digital. RENOTE-Revista Novas Tecnologias na Educação, 3(1). [GS Search]

Fincher, S., \& Petre, M. (Eds.). (2004). Computer science education research. CRC Press. DOI: $\underline{10.1201 / 9781482287325}$ [GS Search]

Fletcher, G. H., \& Lu, J. J. (2009). Education Human computing skills: rethinking the K-12 experience. Communications of the ACM, 52(2), 23-25. DOI: $10.1145 / 1461928.1461938$ [GS Search]

Fontelles, M. J., Simões, M.G., Farias, S. H. \& Fontelles, R. G. S. (2009). Metodologia da pesquisa científica: diretrizes para a elaboração de um protocolo de pesquisa. Revista Paraense de Medicina. 23(3) [GS Search]

França, R. S., \& do Amaral, H. J. C. (2013). Ensino de Computação na Educação Básica no Brasil: Um Mapeamento Sistemático. In XXI Workshop sobre Educação em Computação. [GS Search]

Huang, W., \& Looi, C. K. (2020). A critical review of literature on "unplugged" pedagogies in K12 computer science and computational thinking education. Computer Science Education, 129. DOI: $10.1080 / 08993408.2020 .1789411$ [GS Search]

Hubwieser, P., Armoni, M., Giannakos, M. N., \& Mittermeir, R. T. (2014). Perspectives and visions of computer science education in primary and secondary $(\mathrm{K}-12)$ schools. $A C M$ Transactions on Computing Education (TOCE), 14(2), 1-9. DOI: 10.1145/2602482 [GS Search]

Israel-Fishelson, R., \& Hershkovitz, A. (2020). Persistence in a game-based learning environment: The case of elementary school students learning computational thinking. Journal of Educational Computing Research, 58(5), 891-918. DOI: $\underline{10.1177 / 0735633119887187}$ [GS Search] 
Lee, L. K., Cheung, T. K., Ho, L. T., Yiu, W. H., \& Wu, N. I. (2019). Learning Computational Thinking Through Gamification and Collaborative Learning. In International Conference on Blended Learning (pp. 339-349). Springer, Cham. DOI: 10.1007/978-3-030-21562-0_28 [GS Search]

Leonard, A. E., Daily, S. B., Jörg, S., \& Babu, S. V. (2020). Coding moves: Design and research of teaching computational thinking through dance choreography and virtual interactions. Journal of Research on Technology in Education, 1-19. DOI: 10.1080/15391523.2020.1760754 [GS Search]

Lopes, A. F., Santana, T. S., \& Braga, A. H. (2020). O ensino de pensamento computacional por meio de jogos desplugados e olimpíadas científicas: um relato de experiência nos anos finais do ensino fundamental. In Anais do XXVIII Workshop sobre Educação em Computação (pp. 96-100). SBC. DOI: 10.5753/wei.2020.11137 [GS Search]

Marques, S., da Cruz, M. K., \& Schulz, F. (2019). Formação Continuada de Licenciados em Computação para Trabalho com Computação na Escola. In Anais dos Workshops do Congresso Brasileiro de Informática na Educação (Vol. 8, No. 1, p. 31). DOI: 10.5753/cbie.wcbie.2019.31 [GS Search]

Ministério da Educação e Cultura - MEC (2016) <encurtador.com.br/eBOU2> Acesso em, 22 de agosto de 2020.

Mioto, F., Petri, G., von Wangenheim, C. G., Borgatto, A. F., \& Pacheco, L. H. M. (2019). bASES21-Um Modelo para a Autoavaliação de Habilidades do Século XXI no Contexto do Ensino de Computação na Educação Básica. Revista Brasileira de Informática na Educação, 27(01), 26. DOI: 10.5753/rbie.2019.27.01.26 [GS Search]

Oliveira, E., Bittencourt, R., \& Trindade, R. (2019). Designing and Evaluating a Computational Thinking Course for K-12 Brazilian Educators. In Anais dos Workshops do Congresso Brasileiro de Informática na Educação (Vol. 8, No. 1, p. 1094). DOI: $\underline{10.5753 / \text { cbie.wcbie.2019.1094 [GS Search] }}$

Oliveira, W., França, R., Lemos, A., da Cruz, M. K., Scaico, P., Amaral, H., \& Teixeira, L. P. (2020). Os Desafios Enfrentados pela Licenciatura em Computação que a Comunidade de Educação em Computação Precisa Conhecer. In Anais do XXVIII Workshop sobre Educação em Computação (pp. 191-195). SBC. DOI: 10.5753/wei.2020.11156 [GS Search]

Proctor, C., Bigman, M., \& Blikstein, P. (2019). Defining and designing computer science education in a k12 public school district. In Proceedings of the 50th ACM Technical Symposium on Computer Science Education (pp. 314-320). DOI: $\underline{10.1145 / 3287324.3287440}$ [GS Search]

Román-González, M., Moreno-León, J., \& Robles, G. (2019). Combining assessment tools for a comprehensive evaluation of computational thinking interventions. In Computational thinking education (pp. 79-98). Springer, Singapore. DOI: 10.1007/978-981-13-6528-7_6 [GS Search]

Santana, B., Araujo, L., \& Bittencourt, R. (2020). Computação e sociedade: Livro do professor. Feira de Santana:[sn]. [GS Search]

Santana, B., Araujo, L., \& Bittencourt, R. (2020). Computação e sociedade: Livro do estudante. Feira de Santana:[sn]. [GS Search]

Santana, S. J., \& Oliveira, W. (2019). Desenvolvendo o Pensamento Computacional no Ensino Fundamental com o uso do Scratch. In Anais do Workshop de Informática na Escola (Vol. 25, No. 1, p. 158). DOI: 10.5753/cbie.wie.2019.158 [GS Search] 
Santos, A., Gama, R., \& Farias, C. (2019). Computação desplugada no ensino da Computação no Brasil: um mapeamento sistemático da literatura. In Anais da XIX Escola Regional de Computação Bahia, Alagoas e Sergipe (pp. 565-574). SBC. [GS Search]

Santos, W. O., Silva, C., \& Hinterholz, L. (2017). Licenciatura em Computação: Desafios e oportunidades na perspectiva do estudante. In Anais do Workshop de Informática na Escola (Vol. 23, No. 1, p. 885). DOI: 10.5753/cbie.wie.2017.885 [GS Search]

Santos, W. O., Silva, F. C., Hinterholz, L. T., Isotani, S., \& Bittencourt, I. I. (2018). Computação Desplugada: Um Mapeamento Sistemático da Literatura Nacional. RENOTE-Revista Novas Tecnologias na Educação, 16(2), 626-635. DOI: 10.22456/1679-1916.89241 [GS Search]

Silva Neto, S., Santos, H., \& dos Santos, W. (2015). ABILSEN: Uma Abordagem para Inclusão do Licenciado em Computação no Ensino Básico. In Anais do XXIII Workshop sobre Educação em Computação (pp. 396-405). SBC. DOI: 10.5753/wei.2015.10256 [GS Search]

Silva, J. V., \& da Silva Alexandre, G. H. (2020). Um Ambiente Virtual Colaborativo para o Planejamento de Ensino PBL em Cursos de Computação. In Anais do XXVIII Workshop sobre Educação em Computação (pp. 41-45). SBC. DOI: 10.5753/wei.2020.11126 [GS Search]

Sociedade Brasileira de Computação -SBC (2019) https://www.sbc.org.br/documentos-da$\underline{\text { sbc/summary/131-curriculos-de-referencia/1177-diretrizes-para-ensino-de-computacao-na- }}$ educacao-basica. Acesso em 15 de setembro de 2020.

Sociedade Brasileira de Computação -SBC (2018) https://www.sbc.org.br/documentos-dasbc/send/133-estatisticas/1287-estatisticas-computacao-2018. Acesso em 11 de janeiro de 2021.

Tonbuloglu, B., \& Tonbuloglu, I. (2019). The Effect of Unplugged Coding Activities on Computational Thinking Skills of Middle School Students. Informatics in Education, 18(2), 403-426. DOI: 10.15388/infedu.2019.19 [GS Search]

Vasconcellos, C. Metodologia Dialética em Sala de Aula. In: Revista de Educação AEC. Brasília: abril de 1992 (n. 83). [GS Search]

von Wangenheim, C. G., Araújo, G., de Medeiros, S., Missfeldt Filho, R., Petri, G., da Cruz Pinheiro, F.,... \& Hauck, J. C. (2020). Desenvolvimento e Avaliação de um Jogo de Tabuleiro para Ensinar o Conceito de Algoritmos na Educação Básica. Revista Brasileira de Informática na Educação, 27(03), 310. DOI: 10.5753/rbie.2019.27.03.310 [GS Search]

\section{Apêndice A. Questionário usado no primeiro encontro (brainstorm)}

1) Na sua concepção, qual a importância do professor, hoje (várias alternativas podem ser marcadas).

Extremamente importante, é um agente de transformação.

$\square$ É extremamente importante porque pode trazer aos alunos o conhecimento necessário para o presente e o futuro.

$\square$ Muito importante, pode auxiliar a muitos alunos.

$\square$ Tem importância relativa, pois mesmo com bons exemplos não consegue que todos os alunos acolham os bons exemplos.

$\square$ Tem pouca importância devido aos atuais fatores sociais e econômicos.

1.1) Sobre capacitações e palestras (várias alternativas podem ser marcadas).

São melhor aproveitadas se o grupo de trabalho contém poucas pessoas. 
$\square$ São necessárias e contribuem para qualificar as aulas com novas atividades.

$\square$ São necessárias, mas pouco contribuem para qualificar as aulas com novas atividades.

$\square$ Precisam ser divertidas para prender a atenção.

$\square$ Não são necessárias, hoje todos os temas são encontrados nas mídias e podem ser discutidos online no lugar de palestras e capacitações presenciais.

$\square$ São pouco necessárias, os debates são repetitivos e pouco contribuem para as aulas.

$\square$ Quando tratam de um tema monótono, mesmo que importante, é difícil acompanhar.

$\square$ São melhor aproveitadas em auditórios para gerar debate mais amplo.

2) Localização da escola e condição sócio-econômica do seu público-alvo:

- Bairro - classe média

- Bairro - classe média baixa

- Bairro - situação de risco

- Centro - classe média

- Centro - classe média baixa

- Centro - situação de risco

- Outro

2.1) Comentar a questão 2:

3) A turma em que atua:

- No geral, apresenta excelente desempenho escolar.

- No geral, apresenta bom desempenho escolar.

- No geral, apresenta baixo desempenho escolar.

- No geral, apresenta baixíssimo desempenho escolar.

3.1) Se atua em uma $2^{\mathrm{a}}$ turma, favor responder:

- No geral, apresenta excelente rendimento escolar.

- No geral, apresenta bom rendimento escolar.

- No geral, apresenta baixo rendimento escolar.

- No geral, apresenta baixíssimo rendimento escolar.

4) O desempenho escolar da turma se deve a (várias alternativas podem ser marcadas):

$\square$ Uma série de fatores familiares, sociais, econômicos, afetivos.

$\square$ Principalmente, pela falta de auxílio da família ou responsáveis.

$\checkmark$ Principalmente, pelo bom auxílio da família ou responsáveis.

$\square$ Principalmente, pela falta de prontidão pessoal para os estudos (o aluno tem boa estrutura familiar, mas não aproveita suas capacidades).

$\square$ Principalmente, pela dificuldade econômico-financeira.

$\square$ Principalmente, por questões afetivas.

$\square$ Principalmente, por questões sociais.

4.1) Esse desempenho reflete no IDEB da turma?

- Sim, reflete.

- Reflete em parte.

○ Não, reflete.

4.2) Qual o IDEB do ano anterior da turma?

○ Muito bom.

- Bom. 
- Necessita melhorar.

- Necessita melhorar muito.

5) Formação básica:

○ Cursei ensino médio convencional.

- Cursei segundo grau científico.

- Cursei segundo grau preparação para o trabalho.

- Cursei Magistério.

○ Outro

6) Formação superior/Informática (várias alternativas podem ser marcadas):

$\square$ Cursei Pedagogia e havia disciplina ou conteúdos de Informática.

$\square$ Cursei outra licenciatura e havia disciplina ou conteúdos de Informática.

$\square$ Cursei bacharelado, após cursei complementação para formação docente e nessa havia disciplina ou conteúdos de Informática

$\square$ Cursei Pedagogia e não havia disciplina ou conteúdos de Informática.

$\square$ Cursei outra licenciatura e não havia disciplina ou conteúdos de Informática.

$\square$ Cursei bacharelado, após cursei complementação para formação docente e não havia disciplina ou conteúdos de Informática.

$\square$ Na graduação cursei uma disciplina de Informática, mas não foi suficiente para utilizar na escola. A carga horária dessa disciplina deveria ser maior.

$\square$ Na graduação cursei uma disciplina de Informática, mas não aproveitei e não consigo aplicar nas escola.

$\square$ Na graduação cursei uma disciplina de Informática, mas foi improdutiva - o professor não soube conduzir.

$\square$ Cursei bacharelado, após cursei complementação para formação docente e nessa não havia disciplina ou conteúdos de Informática

6.1) Se cursou outra licenciatura ou bacharelado, que não Pedagogia, indique a área:

6.2) Sobre informática no Ensino Superior (no curso da universidade).

- Deveria ser obrigatória, ofertada em disciplina específica.

- Deveria ser trabalhada por todos os professores, de todas as disciplinas da graduação.

- Deveria ser ofertada em disciplina opcional ou através de oficinas opcionais.

- Não é necessária ser trabalhada no Ensino Superior.

7) Sobre informática na escola.

○ É importante - deveria ser obrigatória na escola.

- É pouco importante - poderia ser vista às vezes na escola.

- É desnecessária na escola.

7.1) Sobre quem trabalha informática na escola.

- Trabalho o que posso, mas não tenho formação adequada para essa atividade.

- Trabalho somente se for auxiliada por outro colega.

- A informática é trabalhada por outro professor específico da área.

- A informática não é trabalhada na minha escola.

7.2) Se a informática não é trabalhada na sua escola, identifique o motivo:

- Não há professor da área.

- Não há computadores para toda turma.

- Há computadores, mas não sinto segurança para utilizar. 
○ O acesso à internet é precário.

8) Sobre a existência de diferença entre Informática e Computação.

- Não sei se há diferença.

- Se há diferença, não sei qual é.

- Sei que há diferença, mas não sei explicar.

- Sei que há diferença e conheço a diferença.

8.1) Comente a resposta anterior.

9) Participação em atividades de Computação na escola.

- Já tive oportunidade de participar em alguma atividade que aconteceu fora da minha escola.

- Já tive oportunidade de participar em alguma atividade que aconteceu na minha escola.

- Nunca participei.

9.1) Se já participou de atividades de Computação na escola comente com poucas palavras quem ministrou, como foi conduzido e qual era a atividade.

10) Capacitação para trabalhar Computação na Escola.

○ Já participei e gostei do conteúdo.

- Já participei e não gostei do conteúdo.

- Nunca participei.

11) Na sua concepção, as Ciências que devem ser trabalhadas na escola, são (várias alternativas podem ser marcadas):

$\square$ Letras (Leitura/escrita/interpretação e composição textual).

$\square$ Matemática

$\square$ Ciências Sociais, Humanas

$\square$ Ciência Religiosa

$\square$ Computação

$\square$ Arte

$\square$ Esporte e Saúde

$\square$ Educação Financeira

$\square$ Informática

$\square$ Ciências da Natureza

$\square$ História e Geografia

\section{Apêndice B. Questionário usado no segundo encontro}

1) Como você avalia o encontro anterior?

- Muito necessário, contribuiu muito para ampliar atividades de Fundamentos de Computação nas escolas.

- De relevância relativa, pois poderia ser encaminhado de outras formas.

- Teve pouca relevância, uma vez que, a Computação não precisa ser trabalhada na escola.

- Teve pouca relevância, uma vez que, não se consegue trabalhar a Computação na escola.

1.1) $\mathrm{O}$ material didático enviado à você foi recebido corretamente pelo e-mail informado no $1^{\circ}$ encontro? Caso não tenha sido recebido, favor informar seu e-mail. 
1.2) Comente pontos positivos e ou negativos do encontro anterior com a intenção de qualificar os próximos encontros.

2) Sobre a utilização na escola do material didático disponibilizado no $1^{\circ}$ encontro, foi possível utilizar com os estudantes:

$\square$ Algoritmos

$\square$ Parte das atividades de Algoritmos

$\square$ Criptografia

$\square$ Parte das atividades de Criptografia

$\square$ Código Binário

$\square$ Parte das atividades de Código Binário

$\square$ Decomposição

$\square$ Não foi possível trabalhar nenhuma atividade de CD na escola, após o $1^{\circ}$ encontro.

3) Atuo nas seguintes turmas:

$\square 4^{\circ}$ Ano

$\square 5^{\circ}$ Ano

3.3) Ao utilizar o material didático do $1^{\circ}$ encontro observou-se que:

- No geral, a(s) turma(s) apresentou(ram) excelente desempenho ao realizar as atividades.

- As turmas tiveram desempenhos diferentes (muito bons e demonstraram dificuldades para resolver os desafios de CD).

- No geral, apresentou(ram) bom desempenho ao realizar as atividades.

- No geral, apresentou(ram) baixíssimo desempenho ao realizar as atividades.

○ Não se aplica - não foi possível utilizar o material.

3.4) Comente a questão 3.3

3.5) Se não foi possível utilizar o material didático de $\mathrm{CD}$ após o $1^{\circ}$ encontro, quais as estratégias para iniciar a utilização desse com seus estudantes na escola(s)?

4) Qual sua expectativa em relação ao $3^{\circ}$ encontro?

\section{Apêndice C. Questionário usado no terceiro encontro}

1. Estamos no $3^{\circ}$ encontro e já se passaram quase 5 meses de envolvimento com o projeto. Diante das discussões e do material didático, o que você entende sobre Computação Desplugada?

2. O que você entende sobre Pensamento Computacional?

3. O que você entende sobre a diferença entre o ensino de Informática e Computação na escola?

4. Você realizou alguma leitura sobre as temáticas trabalhadas no encontro?

5. Do último encontro até o momento você comentou ou discutiu com colegas, amigos, conhecidos ou familiares sobre Pensamento Computacional ou Computação Desplugada?

6. Qual a importância do material didático produzido para o futuro dos estudantes das escolas? (Quanto maior o valor mais relevante.)

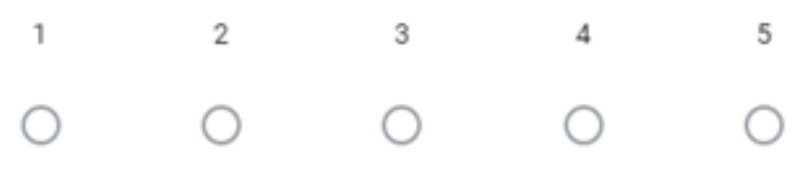


7. Justifique a questão anterior.

8. Como você considera o impacto da seguinte relação sobre a vida do(s) estudante da(s) escola(s):

\section{Computação}

Estudo

Empregabilidade

9. Quais atividades já foram desenvolvidas na escola? Marque todas as já trabalhadas.

Removido para revisão

10. Comente suas impressões sobre o desenvolvimento das atividades na(s) escolas. Como alunos recebem as atividades de Computação Desplugada? Como os colegas professores enxergam as atividades de Computação Desplugada?

11. Como você trabalha as atividades de Computação Desplugada com seus alunos?

12. Como você avalia os encontros realizados até o momento? Tens sugestões?

\section{Apêndice D. Questionário usado no quarto encontro}

1) Como você avalia os encontros da capacitação? (Conteúdos, tempo, horários, organização, desempenho dos responsáveis pela formação, entre outros critérios).

2) Como você avalia o material didático desenvolvido?

3) Quais são as suas sugestões para atividades futuras?

4) Como você avalia o impacto das atividades de Computação Desplugada nos processos de pensamento do seu aluno hoje? (raciocínio computacional)

5) Como você avalia o impacto das atividades de Computação Desplugada no futuro do seu aluno? 